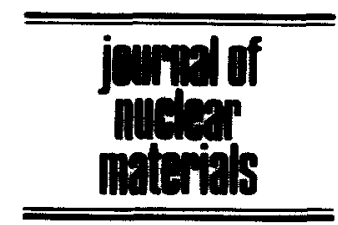

\title{
Effects of irradiation on intergranular stress corrosion cracking
}

\author{
G.S. Was ${ }^{a}$, S.M. Bruemmer ${ }^{\text {b }}$ \\ a Departments of Nuclear Engineering and Materials Science and Engineering, University of Michigan, Ann Arbor, MI 48109, USA \\ ${ }^{\mathrm{b}}$ Pacific Northwest Laboratory, Richland, WA 99352, USA
}

\begin{abstract}
Intergranular stress corrosion cracking (IASCC) is a pervasive and generic problem in current light water reactor and advanced reactor designs that can lead to widespread component failure. IASCC is believed to be due to either to changes in the grain boundary composition, the microstructure or the water chemistry and corrosion potential. Of greatest interest are the changes in composition and microstructure since IASCC exhibits a well-defined, although not invariant, dose threshold. Changes in grain boundary composition are a result of radiation-induced segregation (RIS) and result in enrichment of nickel, depletion of chromium as well as changes in the impurity element compositions at the grain boundary. Although the basic theory of RIS is believed to be understood, quantitative descriptions of observed changes are not yet possible and hinder the correlation between RIS and IASCC. Changes in the microstructure are intimately linked to the strength and ductility of the irradiated alloy and strong correlations between IASCC and irradiated yield strength have been found. However, a fundamental understanding of the deformation mechanisms and the way in which deformation is coupled to IG cracking in alloys irradiated under LWR conditions $\left(250-360^{\circ} \mathrm{C}, 1-5 \mathrm{dpa}\right)$ is lacking. Finally, although radiation is known to affect IGSCC through changes in water chemistry and corrosion potential, it is not a necessary condition. Overshadowing and slowing progress on this important problem is a lack of well-defined-data from properly irradiated and properly characterized materials, due principally to inherent experimental and financial difficulties. As such, the specific mechanism(s) of IASCC remain unknown.
\end{abstract}

\section{Introduction}

Irradiation assisted stress corrosion cracking (IASCC) refers to the acceleration of the SCC process by irradiation. Broadly speaking, IASCC can result from effects on the materials, and/or environment by gammas, neutrons, electrons or ions. However, in a practical sense, the problem is primarily associated with the accelerated intergranular cracking process in austenitic alloys in light water reactor cores by neutron irradiation. Thus, the environment is generally hydrogenated or oxygenated water at $275-330^{\circ} \mathrm{C}$. The identification of the IASCC problem and its characteristics has often been complicated by its manifestation as an acceleration rather than an inducement of a process. Intergranular (IG) SCC in austenitic alloys is a well-established and much studied phenomenon. In many instances, IGSCC of these alloys can occur without the aid of irradiation, and isolating the contribution of irradiation to the observed cracking elevates the difficulty of the problem.

Neutron irradiation promotes IG cracking, Fig. 1, and a decrease in ductility above $\sim 5 \times 10^{20} \mathrm{n} / \mathrm{cm}^{2}$ $(E>1 \mathrm{MeV}$ ), which corresponds to about $0.7 \mathrm{dpa}$ by the NRT [2] displacement model. This demonstrates that the observed behavior is due to irradiation-induced changes in the alloy which may involve microstructure changes, microchemical changes, compositional changes by transmutation, and interactions among these changes. In fact, cracking in neutron irradiated 304 stainless steels has been observed in constant load tests at stresses as low as $19.3 \mathrm{MPa}$ vs. stresses in excess of the yield strength for the unirradiated alloys [3]. Stress also has an important role, and irradiation creep can cause a decrease in stress under displacement-controlled conditions. However, water chemistry effects are also apparent by the decrease in cracking with decreasing dissolved oxygen, for example 


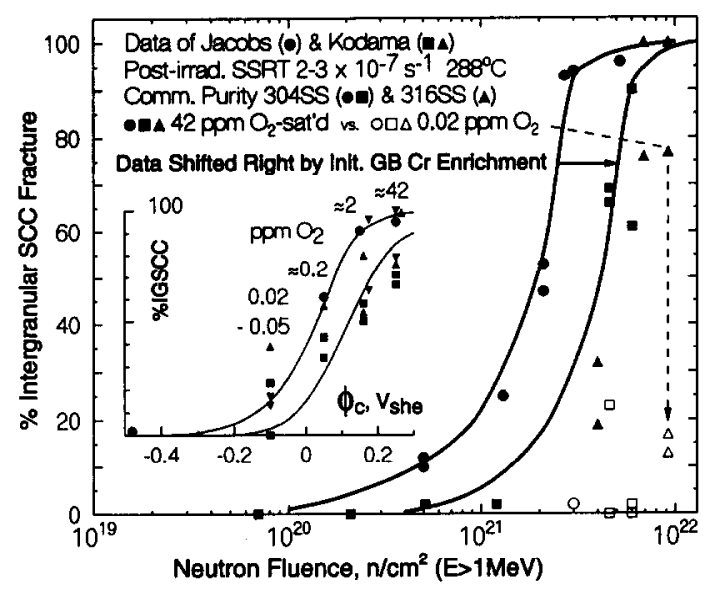

Fig. 1. The effect of fast neutron fluence on IASCC as measured in slow strain tests at $3.7 \times 10^{-7} \mathrm{~s}^{-1}$ on pre-irradiated types 304 and 316 stainless steel in $288^{\circ} \mathrm{C}$ water. The effect of corrosion potential via changes in dissolved oxygen is evident by comparing the closed and open symbols in the main part of the figure. In the inset figure, the effect of corrosion potential is shown for data obtained at several specific fluences. (from Ref. [1]).

at $3 \times 10^{21} \mathrm{n} / \mathrm{cm}^{2}$, Fig. 1. The dissolved oxygen concentration and that of several other oxidizing and reducing radicals are a function of the irradiation type and flux. Hence, the problem is complicated by changes in the water chemistry, microstructure and stress, high- lighting the many-faceted nature of the IASCC problem. This paper focuses on the mechanisms which are believed to be responsible for the observed IASCC in LWRs.

\section{Mechanisms of IASCC}

The mechanisms which have been proposed to explain IASCC may be categorized into either (1) microcompositional effects; radiation-induced segregation of impurities and redistribution of major alloying elements, (2) microstructural changes; radiation hardening through the formation of depleted zones and dislocation loops, and (3) radiation water chemistry; specifically the effects on corrosion potential, solution conductivity and ion chemistry. Unfortunately, the cracking response to changes in water chemistry is similar for both irradiated and unirradiated materials, as will be discussed later [4]. In both cases, there is a steep increase in environmental cracking kinetics with a rise in the corrosion potential to the range -100 to $0 \mathrm{mV}_{\text {she }}$ $[5,6]$. The crack growth rate also increases sharply for solution conductivities above about $0.1 \mu \mathrm{S} / \mathrm{cm}$ in either the irradiated or unirradiated case $[5,6]$. Thus while the corrosion potential (at constant oxygen content) and solution conductivity strongly control the cracking rate under constant water chemistry conditions, the cumulative effect of radiation has a strong

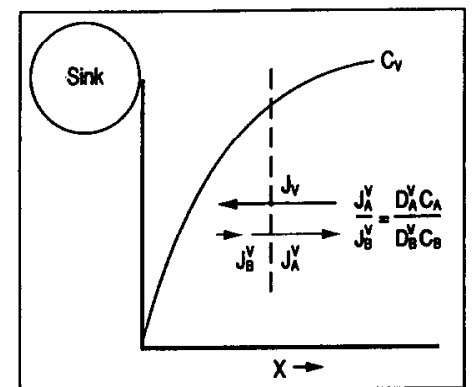

$\mathbf{a}$

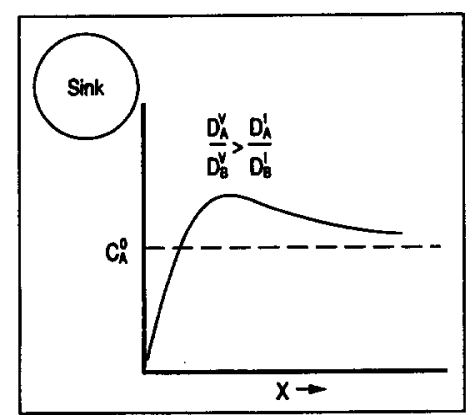

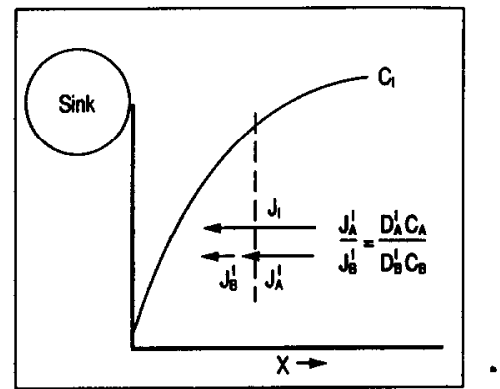

b

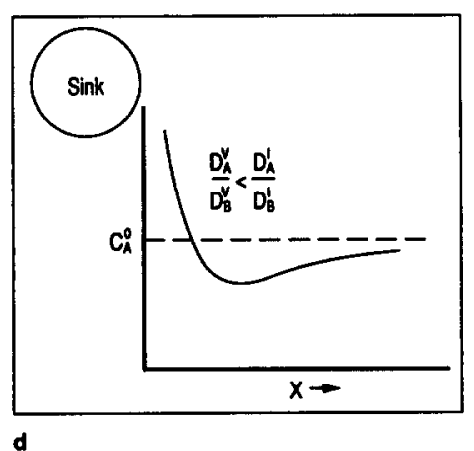

Fig. 2. Schematic illustration of inverse Kirkendall effects induced by (a) vacancy flux and (b) interstitial flux, and (c) and (d) the effect of diffusion coefficients on the depth distribution of $A$ atoms in an $A B$ alloy (from Ref. [7]). 
influence on IASCC as illustrated by a dramatic incrcase in IGSCC susceptibility with flucnce in slow strain rate tests. In fact, there is a distinct (although not invariant) threshold fluence at which IASCC is observed under LWR conditions. The existence of a threshold fluence for IASCC susceptibility indicates that while in-situ cffects (corrosion potential, conductivity, temperature) are important, only 'persistent' radiation effects (microstructural and microchemical changes) can be responsible for the behavior in postirradiation tests. The following sections will address the mechanisms by which radiation affects alloy composition, microstructure and mechanical properties, and the mechanisms by which water chemistry and corrosion potential can affect crack growth.

\subsection{Radiation-induced segregation}

Most of the recent attention has been focused on the issue of radiation-induced segregation (RIS) of impurities to grain boundaries as being the main cause of the 'weakening' of the grain boundaries. This segregation process is fundamentally different from thermal segregation in that it is driven by the flux of radiationproduced defects to sinks such as the free surface, grain boundaries, and other interfaces [7]. Vacancies and intcrstitials are the basic defects produced by irradiation and can reach concentrations which are orders of magnitude greater that the thermal equilibrium concentration. Diffusion of solutes by vacancy or interstitial mechanisms is then accelerated by the elevated concentration of these defects. $\Lambda$ s a function of temperature, segregation peaks at intermediate temperatures since a lack of mobility shuts down the process at low temperatures, and recombination dominates at high temperatures where defect concentrations approach their thermal equilibrium values. If the relative participation of alloying elements in the defect fluxes is not the same as the relative concentration of the alloying elements, then a net transport of the constituents to or from the sinks will occur, Fig. 2. The result will be either a buildup or a depletion of alloying elements at the sinks - principally grain boundaries and free surfaces. The magnitude of the buildup/ depletion is dependent upon several factors such as whether a constituent migrates more rapidly by one defect mechanism or another, and the binding between solutes and defects.

A common characteristic of RIS profiles is their narrowness, often confined to within 5 to $10 \mathrm{~nm}$ of the grain boundary. Irradiation of stainless steels results in the redistribution of the major alloying elements and the segregation of impurities. RIS studies have shown that $\mathrm{Ni}$ segregates to the grain boundaries while $\mathrm{Cr}$ and $F e$ are depleted at the boundaries. With regard to impurities, $\mathrm{P}, \mathrm{S}$ and $\mathrm{Si}$ are known to become enriched and minor alloying elements such as Mo and $\mathrm{Ti}$ are depleted at the grain boundarics. Intcrestingly, the directions of segregation are consistent with an atomic volume effect in which the subsized solute migrates preferentially with the interstitial flux, and the oversized solute participates preferentially in the vacancy flux. The following scetion provides a description of RIS which can be used to understand results of experiments.

\subsubsection{Modeling radiation-induced segregation}

Since our interests arc on the segrcgation behavior in ternary $\mathrm{Fe}-\mathrm{Cr}-\mathrm{Ni}$ alloys, the framework of the phenomenological model for ternary alloys will be briefly described. The following description is a condensation of that given by Lam et al. [8] for a ternary alloy whose components $\mathrm{A}, \mathrm{B}$ and $\mathrm{C}$ are present in concentrations $C_{\mathrm{A}}, C_{\mathrm{B}}$ and $C_{\mathrm{C}}$ (number of atoms per unit volume). Vacancy and interstitial concentrations created during irradiation vary with time according to

$\frac{\partial C_{\mathrm{v}}}{\partial t}=-\nabla \cdot J_{\mathrm{v}}+K-R$,

$\frac{\partial C_{\mathrm{i}}}{\partial t}=-\boldsymbol{\nabla} \cdot \boldsymbol{J}_{\mathrm{i}}+K-R$,

where $\boldsymbol{\nabla} \cdot J_{\mathrm{v}}$ and $\boldsymbol{\nabla} \cdot J_{\mathrm{i}}$ are the divergences of the vacancy and interstitial fluxes at the defect sinks and $K$ and $R$ are the local total rates of production and mutual recombination, respectively, of point defects. The defect fluxes are partitioned into those occurring via $\mathrm{A}, \mathrm{B}$ and $\mathrm{C}$ atoms in the alloy according to

$\boldsymbol{J}_{\mathrm{i}}=\boldsymbol{J}_{\mathrm{i}}^{\mathrm{A}}+\boldsymbol{J}_{\mathrm{i}}^{\mathrm{B}}+\boldsymbol{J}_{\mathrm{i}}^{\mathrm{C}}$,

$J_{\mathrm{v}}=J_{\mathrm{v}}^{\mathrm{A}}+\boldsymbol{J}_{\mathrm{v}}^{\mathrm{B}}+\boldsymbol{J}_{\mathrm{v}}^{\mathrm{C}}$,

where the subscripts indicate the species of flux and the superscripts indicate the complementary species by which the flux occurs. The partial interstitial fluxes are in the same direction as the corresponding atom fluxes while the partial vacancy fluxes are in the opposite direction to the atom fluxes,

$J_{\mathrm{i}}^{\mathrm{A}}=J_{\mathrm{A}}^{\mathrm{i}}, \quad J_{\mathrm{i}}^{\mathrm{B}}=J_{\mathrm{B}}^{\mathrm{i}}, \quad J_{\mathrm{i}}^{\mathrm{C}}=J_{\mathrm{C}}^{\mathrm{i}}$,

$J_{\mathrm{v}}^{\mathrm{A}}=-J_{\mathrm{A}}^{\mathrm{v}}, \quad J_{\mathrm{v}}^{\mathrm{B}}=-J_{\mathrm{B}}^{\mathrm{v}}, \quad J_{\mathrm{v}}^{\mathrm{C}}=-J_{\mathrm{C}}^{\mathrm{v}}$,

and Eqs. (2) can be written as

$J_{\mathrm{i}}=J_{\mathrm{A}}^{\mathrm{i}}+J_{\mathrm{B}}^{\mathrm{i}}+J_{\mathrm{C}}^{\mathrm{i}}$,

$J_{\mathrm{v}}=-\left(J_{\mathrm{A}}^{\mathrm{v}}+J_{\mathrm{B}}^{\mathrm{v}}+J_{\mathrm{C}}^{\mathrm{v}}\right)$.

These equations express the coupling between defect and atom fluxes across any fixed lattice plane. In general, the partitioning of the interstitial and vacancy fluxes via $A, B$ and $C$ atoms is not in the same proportion as the atom fractions in the alloy. Interstitials may preferentially migrate by one atom type while vacancies preferentially exchange with another atom 
type. This preferential coupling of defect and atom fluxes is the physical origin of radiation-induced segregation.

As with the defect compositions, the alloy composition in time and space can be described by the conservation equations

$$
\begin{aligned}
& \frac{\partial C_{\mathrm{A}}}{\partial t}=-\nabla \cdot J_{\mathrm{A}}, \\
& \frac{\partial C_{\mathrm{B}}}{\partial t}=-\nabla \cdot J_{\mathrm{B}}, \\
& \frac{\partial C_{\mathrm{C}}}{\partial t}=-\nabla \cdot J_{\mathrm{C}},
\end{aligned}
$$

where $J_{\mathrm{A}}, J_{\mathrm{B}}$ and $J_{\mathrm{C}}$ are the total fluxes of the alloying elements, which can be partitioned into partial fluxes occurring by vacancies and interstitials,

$J_{\mathrm{A}}=\boldsymbol{J}_{\mathrm{A}}^{\mathrm{i}}+\boldsymbol{J}_{\mathrm{A}}^{\mathbf{v}}$,

$J_{\mathrm{B}}=J_{\mathrm{B}}^{\mathrm{i}}+J_{\mathrm{B}}^{\mathrm{v}}$

$J_{\mathrm{C}}=J_{\mathrm{C}}^{\mathrm{i}}+J_{\mathrm{C}}^{\mathbf{v}}$.

The defect and atom fluxes are expressed in terms of the concentration gradients of the different species,

$J_{\mathrm{k}}^{\mathrm{i}}\left(\equiv J_{\mathrm{i}}^{\mathrm{k}}\right)=-D_{\mathrm{k}}^{\mathrm{i}} \alpha \nabla C_{\mathrm{k}}-D_{\mathrm{i}}^{\mathrm{k}} \nabla C_{\mathrm{i}}$,

$J_{\mathrm{k}}^{\mathrm{v}}\left(\equiv-J_{\mathrm{v}}^{\mathrm{k}}\right)=-D_{\mathrm{k}}^{\mathrm{v}} \boldsymbol{\alpha} \nabla C_{\mathrm{k}}+D_{\mathrm{v}}^{\mathrm{k}} \nabla C_{\mathrm{v}}$,

where $k=\mathrm{A}, \mathrm{B}$ or $\mathrm{C}, \alpha$ is the thermodynamic factor which relates the concentration gradient to the chemical potential gradient of atoms, and $D_{k}^{\mathrm{i}} D_{k}^{\mathrm{v}}, D_{\mathrm{i}}^{k}$ and $D_{\mathrm{v}}^{k}$ are the partial diffusion coefficients of atoms $k$ by interstitials, and vacancies, and of interstitials and vacancies by atoms, respectively. The partial diffusion coefficients have the form

$D_{\mathrm{k}}^{\mathrm{j}}=d_{\mathrm{kj}} N_{\mathrm{j}}$ and $D_{\mathrm{j}}^{\mathrm{k}}=d_{\mathrm{kj}} N_{\mathrm{k}}$,

where $j=\mathrm{i}$ or $\mathrm{v}, N_{j}=\Omega C_{j}$ and $N_{k}=\Omega C_{k}$ are the atomic fractions of defects and of $k$ atoms, respectively, $\Omega$ is the average atomic volume in the alloy, and $d_{k j}$ are the diffusivity coefficients for conjugate atomdefect pairs $k j$,

$d_{k \mathrm{j}}=\frac{1}{6} \lambda_{\mathrm{k}}^{2} z_{k} \nu_{\mathrm{kj}}^{\text {eff }}$

Here $\lambda_{k}$ is the jump distance, $z_{k}$ the coordination number, and $\nu_{\mathrm{kj}}^{\text {eff }}$ the effective jump or exchange frequency of the pair. The total diffusion coefficients for interstitials and vacancies are defined as

$D_{\mathrm{i}}=\sum_{\mathrm{k}} d_{\mathrm{ki}} N_{\mathrm{k}}$,

$D_{\mathrm{v}}=\sum_{\mathrm{k}} d_{\mathrm{kv}} N_{\mathrm{k}}$,

and for atoms

$D_{k}=d_{k \mathrm{i}} N_{\mathrm{i}}+d_{k \mathrm{v}} N_{\mathrm{v}}$.
From Eqs. (4), (6), (7), (8) and (10), the defect and atom fluxes with respect to a coordinate system fixed on the crystal lattice are

$$
\begin{aligned}
J_{\mathrm{i}}= & -\left(d_{\mathrm{Ai}}-d_{\mathrm{Ci}}\right) \Omega C_{\mathrm{i}} \alpha \nabla C_{\mathrm{A}}-\left(d_{\mathrm{Bi}}-d_{\mathrm{Ci}}\right) \Omega C_{\mathrm{i}} \alpha \nabla C_{\mathrm{B}} \\
& -D_{\mathrm{i}} \nabla C_{\mathrm{i}}, \\
J_{\mathrm{v}}= & \left(d_{\mathrm{Av}}-d_{\mathrm{Cv}}\right) \Omega C_{\mathrm{v}} \alpha \nabla C_{\mathrm{A}}+\left(d_{\mathrm{Bv}}-d_{\mathrm{Cv}}\right) \Omega C_{\mathrm{v}} \alpha \nabla C_{\mathrm{B}} \\
& -D_{\mathrm{v}} \nabla C_{\mathrm{v}}, \\
J_{\mathrm{A}}= & -D_{\mathrm{A}} \alpha \nabla C_{\mathrm{A}}+d_{\mathrm{Av}} \Omega C_{\mathrm{A}} \nabla C_{\mathrm{v}}-d_{\mathrm{Ai}} \Omega C_{\mathrm{A}} \nabla C_{\mathrm{i}}, \\
J_{\mathrm{B}}= & -D_{\mathrm{B}} \alpha \nabla C_{\mathrm{B}}+d_{\mathrm{Bv}} \Omega C_{\mathrm{B}} \nabla C_{\mathrm{v}}-d_{\mathrm{Bi}} \Omega C_{\mathrm{B}} \nabla C_{\mathrm{i}}, \\
J_{\mathrm{C}}= & -D_{\mathrm{C}} \alpha \nabla C_{\mathrm{C}}+d_{\mathrm{Cv}} \Omega C_{\mathrm{C}} \nabla C_{\mathrm{v}}-d_{\mathrm{Ci}} \Omega C_{\mathrm{C}} \nabla C_{\mathrm{i}}
\end{aligned}
$$

Small perturbations arising from the presence of point defects are neglected so that $C_{\mathrm{A}}+C_{\mathrm{B}}+C_{\mathrm{C}}=\Omega^{-1}$ and $\nabla C_{C}=-\left(\nabla C_{A}+\nabla C_{B}\right)$. Of the five flux equations (11a)-(11e), only four are independent because the defect and atom fluxes across a marker plane must balance,

$J_{\mathrm{A}}+J_{\mathrm{B}}+J_{\mathrm{C}}=J_{\mathrm{i}}-J_{\mathrm{v}}$.

A system of four coupled partial differential equations describing the space and time dependence of the atoms and defects in the solid is determined by substituting the defect and atom fluxes given by Eqs. (11) into Eqs. (1) and (5),

$$
\begin{aligned}
\frac{\partial C_{\mathrm{v}}}{\partial t}= & \nabla \cdot\left[-\left(d_{\mathrm{Av}}-d_{\mathrm{Cv}}\right) \Omega C_{\mathrm{v}} \alpha \nabla C_{\mathrm{A}}\right. \\
& \left.-\left(d_{\mathrm{Bv}}-d_{\mathrm{Cv}}\right) \Omega C_{\mathrm{v}} \alpha \nabla C_{\mathrm{B}}+D_{\mathrm{v}} \nabla C_{\mathrm{v}}\right]+K-R,
\end{aligned}
$$

$$
\begin{aligned}
\frac{\partial C_{\mathrm{i}}}{\partial t}= & \nabla \cdot\left[\left(d_{\mathrm{Ai}}-d_{\mathrm{Ci}}\right) \Omega C_{\mathrm{i}} \alpha \nabla C_{\mathrm{A}}\right. \\
& \left.+\left(d_{\mathrm{Bi}}-d_{\mathrm{Ci}}\right) \Omega C_{\mathrm{i}} \alpha \nabla C_{\mathrm{B}}+D_{\mathrm{i}} \nabla C_{\mathrm{i}}\right]+K-R,
\end{aligned}
$$

$\frac{\partial C_{\mathrm{A}}}{\partial t}=\nabla \cdot\left[D_{\mathrm{A}} \alpha \nabla C_{\mathrm{A}}+\Omega C_{\mathrm{A}}\left(d_{\mathrm{Ai}} \nabla C_{\mathrm{i}}-d_{\mathrm{Av}} \nabla C_{\mathrm{v}}\right)\right]$,

$\frac{\partial C_{\mathrm{B}}}{\partial t}=\nabla \cdot\left[D_{\mathrm{B}} \alpha \nabla C_{\mathrm{B}}+\Omega C_{\mathrm{B}}\left(d_{\mathrm{Bi}} \nabla C_{\mathrm{i}}-d_{\mathrm{Bv}} \nabla C_{\mathrm{v}}\right)\right]$.

Numerical solutions of Eqs. (13) are obtained for a planar sample under irradiation with energetic particles with the aid of the GEAR package of subroutines [9]. In studying grain boundary segregation, the grain boundary is equated to a free surface and the calculations are performed for only a single grain, taking advantage of the symmetry of the problem. The initial conditions are the thermodynamic equilibrium of the alloy. Conditions at the boundary are defined as follows. At the grain center, all concentration gradients 
are set equal to zero. At the grain boundary, the concentrations of interstitials and vacancies are fixed at their thermal equilibrium values. The grain boundary atom concentrations are determined by the conservation of the numbers of atoms in the specimen. Atom concentrations are assumed to be initially uniform. Parameters used in the calculation of segregation in $\mathrm{Fe}-\mathrm{Cr}-\mathrm{Ni}$ alloys are given in Ref. [8] for the Lam model and in Ref. [10] for the Perks model as coded by Simonen [11].

\subsubsection{Particle type and efficiency}

IASCC is being studied using a variety of particle types (neutrons, electrons, protons and heavy ions) and energies. This poses a problem in equivalence of irradiation damage. The basic (measurable) dose unit for neutron irradiation is $\mathrm{n} / \mathrm{cm}^{2}$ above some energy threshold ( $E>x \mathrm{MeV}$ ), where $x$ is the energy threshold. For charged particles it is the time-integrated current or charge, $Q / \mathrm{cm}^{2}$. The particle beam community is accustomed to reporting dose in units of dpa and dose rate as $\mathrm{dpa} / \mathrm{s}$ using one of several models for the determination of dpa. Although somewhat more complicated, due to the existence of an energy spectrum rather than a monoenergetic ion beam, the same conversion can be made from $\mathrm{n} / \mathrm{cm}^{2}(E>x \mathrm{MeV})$, although it is seldom done. Radiation damage, in the form of the number of displacements per atom, is generally determined using some form of the Kinchen-Pease (K-P) displacement model [12] given by

$\nu(T)=0.8 T_{\text {damage }} / 2 E_{\mathrm{d}}$,

where $T_{\text {damage }}$ is the energy transferred from the incoming particle to the struck atom, and $E_{\mathrm{d}}$ is the displacement energy, i.e. that energy needed to displace the struck atom from its lattice position. However, the value of dpa calculated using such a displacement model is not the appropriate unit to be used for dose comparisons between particle types. The reason is the difference in the primary damage state among different particle types.

Fig. 3 shows the relationship between damage morphology (as quantified by the average energy transfer in a PKA collision) and the displacement efficiency for various particle types impinging on a sample of pure nickel at $1 \mathrm{MeV}$. The displacement efficiency is defined as the fraction of the 'ballistically' produced Frenkel pairs (FPs) which survive the cascade quench and are available for long-range migration. These are referred to variously as 'freely migrating' [13] or 'available migrating' [14] defects. They are the principal defects which will affect the amount of grain boundary segregation; our measure of radiation effect. The fraction of the total number of defects produced which are 'freely migrating' is termed the displacement effi-
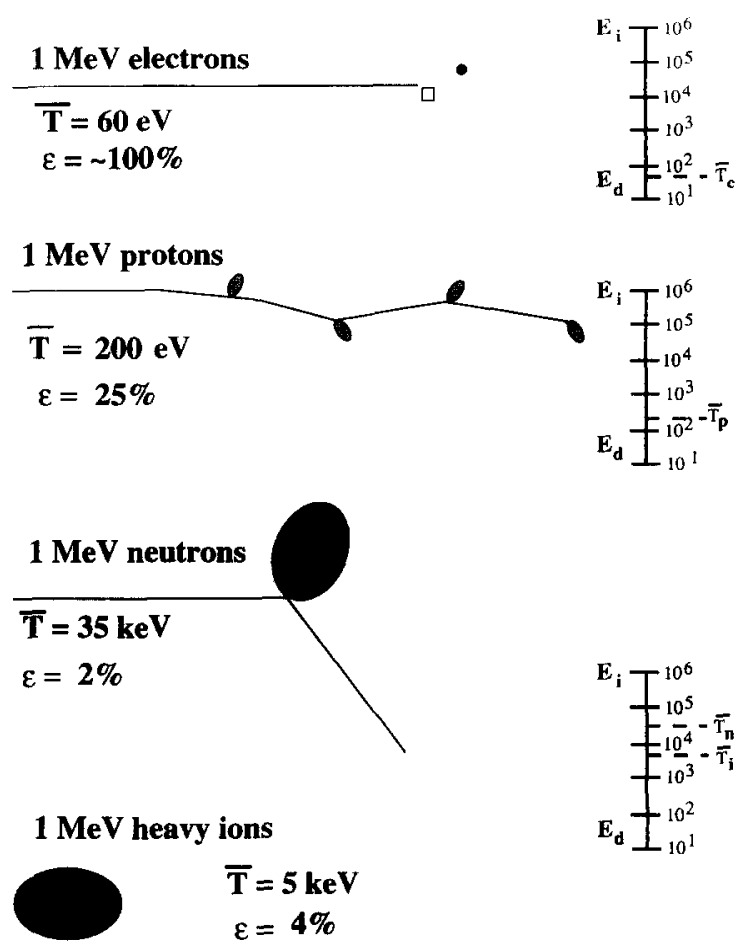

Fig. 3. Description of damage morphologies for irradiation with various particles of the same energy. $T$ is the average energy transfer per PKA and $\epsilon$ is the efficiency of producing freely migrating defects available to affect radiation-induced segregation.

ciency, $\varepsilon$. Despite the equivalence in energy among the four particle types shown, the average energy transferred and the defect production efficiencies vary by almost two orders of magnitude! This is explained by the differences in the cascade morphology among the different particle types. Neutrons and heavy ions produce dense cascades which result in substantial recombination during the cooling or quenching phase. However, electrons are just capable of producing a few widely spaced FPs which have a low probability of recombination. Protons produce small widely spaced cascades and many isolated FPs due to the Coulomb interaction and therefore, fall between the extremes in displacement efficiency defined by electrons and neutrons.

We will focus on the comparison between four types of particle irradiation in order to outline a methodology for establishing equivalence between neutron and charged particle irradiation. The four types are given in Table 1 and are taken from experiments conducted to study the IASCC problem [15-18]. Each experiment is characterized by the particle type and energy, irradiation temperature, reported dose rate and reported total dose. The displacement efficiency is calculated using Naundorf's model [19] which is based on two 


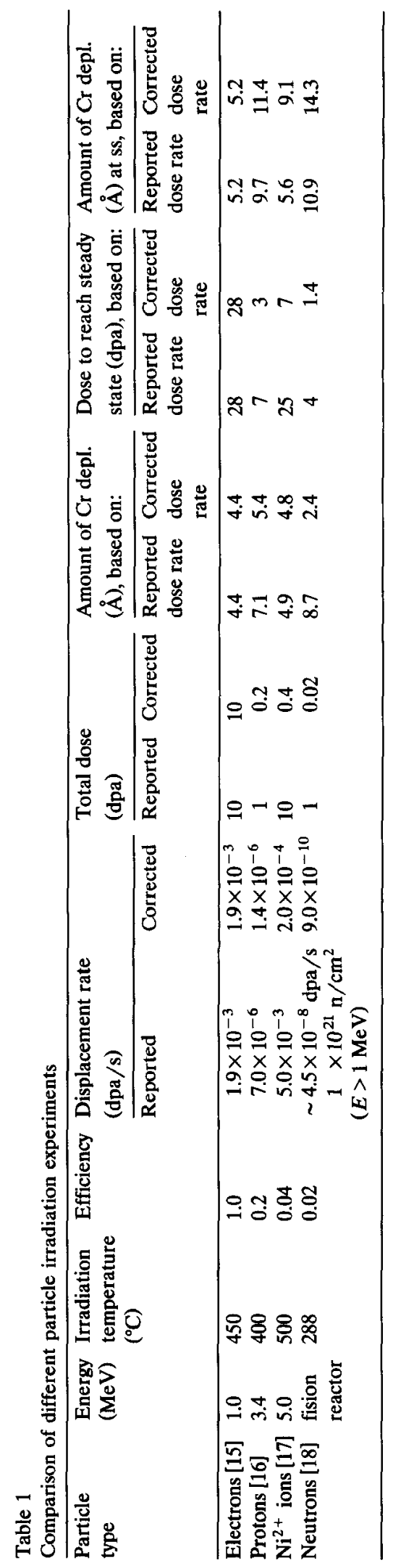


factors. The first is that energy transfer to atoms is only sufficient to create a single FP. The second is that the FPs lie outside a recombination (interaction) radius so that the nearby FPs neither recombine nor cluster. The model follows each generation of the collision and calculates the fraction of all defects produced that remain free. According to Naundorf, the free single FPs are classified according to the generation $i$ in which they were produced, i.e. the relative amount $\eta_{1}$ is that amount which is produced by primary collisions (first generation), while $\eta_{2}$ is the relative amount produced by secondary collisions (second gencration). Thus the total number of free single FPs produced is

$\eta=\sum_{i} \eta_{i}$

where that produced by primary collisions is

$\eta_{1}=\frac{\beta_{\mathrm{p}}}{\sigma_{\mathrm{d}}} \int_{E_{\mathrm{d}}}^{\alpha E} \mathrm{~d} T K_{\mathrm{I}, \mathrm{A}}(E, T)$,

and that produced by secondary collisions is

$$
\begin{aligned}
\eta_{2}= & \frac{1}{\sigma_{\mathrm{d}}} \int_{E_{\mathrm{d}}}^{\alpha E} \mathrm{~d} T K_{\mathrm{I}, \mathrm{A}}(E, T)\left[Z(T) \beta_{\mathrm{A}}(T) / \sigma_{\mathrm{A}}(T)\right] \\
& \times \int_{E_{\mathrm{d}}}^{2.5 E_{\mathrm{d}}} \mathrm{d} T^{\prime} K_{\mathrm{A}, \mathrm{A}}\left(T, T^{\prime}\right) .
\end{aligned}
$$

The primary displacement cross section for the incident ion is

$\sigma_{\mathrm{p}}=\int_{E_{\mathrm{d}}}^{\alpha E} \mathrm{~d} T K_{\mathrm{I}, \mathrm{A}}(E, T)$,

and the total displacement cross section $\sigma_{\mathrm{d}}$ is given in the Kinchen-Pease model by

$\sigma_{\mathrm{d}}=\int_{E_{\mathrm{d}}}^{\alpha E} \mathrm{~d} T K_{\mathrm{I}, \mathrm{A}}(E, T) \nu(T)$.

$K_{\mathrm{I}, \mathrm{A}}(E, T)$ is defined as the differential cross section of an incident ion (I) of energy $E$ which transfers the energy $T \leqslant T_{\max }$ to an atom (A), of the crystal, $E_{\mathrm{d}}$ is the displacement energy, the maximum energy transferred is $\alpha E\left(\alpha=4 M_{\mathrm{I}} M_{\mathrm{A}} /\left(M_{\mathrm{I}}+M_{\mathrm{A}}\right)^{2}\right)$ and $\nu(T)$ is the K-P displacement function defined earlier. $Z(T)$ is the total number of secondary collisions produced above $E_{\mathrm{d}}$ by a primary of energy $T$ along its path. The distance $\lambda$ between two primary collisions is distributed according to an exponential law,

$W(\lambda)=1 / \lambda_{\mathrm{p}} \exp \left(-\lambda / \lambda_{\mathrm{p}}\right)$,

with the mean distance

$\lambda_{\mathrm{p}}=\Omega / \sigma_{\mathrm{p}}$,

where $\Omega$ is the atomic volume. The condition that the distance between two consecutive collisions must be larger than an appropriate interaction radius, $r_{\text {iv }}$ (so

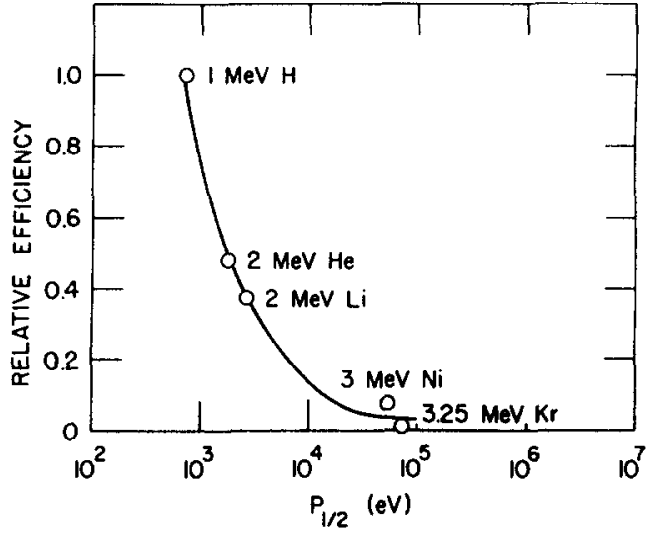

Fig. 4. Relative efficiencies of various ions for producing long-range migrating defects at elevated temperature plotted as a function of the weighted-average recoil energy (from Ref. [20]).

that FPs produced near each other neither recombine nor cluster) reduces the amount of all possible free single FPs by

$\beta_{\mathrm{p}}=\exp \left(-r_{\mathrm{iv}} / \lambda_{\mathrm{p}}\right)$.

Results of the model are the displacement efficiencies shown for the four particle types in Table 1. The 'corrected' displacement rate and 'corrected' total dose for each particle type are determined by multiplying the reported (uncorrected) values times the efficiency factor. Measurements of the relative efficiencies (normalized to that of $1 \mathrm{MeV}$ protons) for defect production as a function of the defect-production weightedaverage recoil energy, $P_{1 / 2}$ are shown in Fig. 4. $P_{1 / 2}$ is the primary recoil energy above and below which half of the defects are produced. It gives a measure of the spatial distribution of the defect production; the larger the value of $P_{1 / 2}$, the greater is the tendency for defects to be produced in cascades rather than as isolated defects. This figure provides a quantitative representation of the relative efficiency for producing solute redistribution at elevated temperatures as a function of the hardness of the primary recoil spectrum.

\subsubsection{Model results}

As a means of comparing the expected measured amount of grain boundary segregation for each of the irradiations described in Table 1, the Lam model [8] was used to simulate the depletion of chromium at the grain boundary of 304 stainless steel of composition $\mathrm{Fe}-20 \mathrm{Cr}-9 \mathrm{Ni}$. Numerical solutions are made for a sample under uniform irradiation with energetic particles assuming a spatially uniform production rate of defects for each particle type. Particle type is identified by the input displacement rate. Model calculations are 


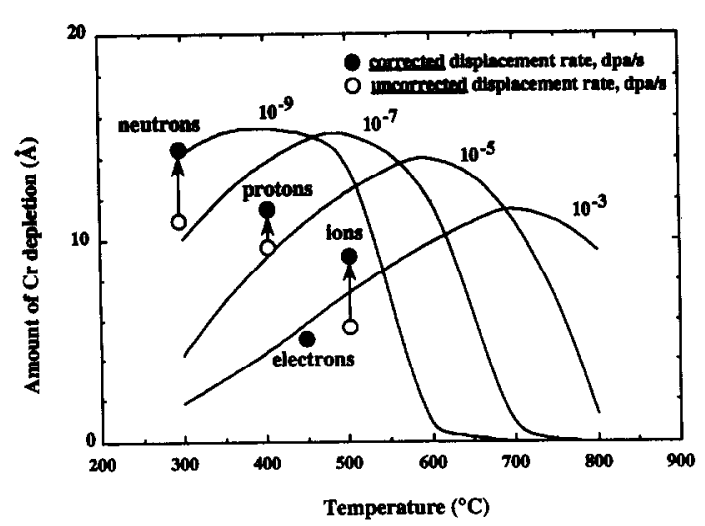

Fig. 5. Comparison of the amount of chromium depletion at steady state, as a function of temperature, dose rate, and displacement efficiency for each particle type. The symbols represent the reported (uncorrected), and efficiency-corrected dose rates for each particle type under the steady state conditions reported in Table 1.

made using the same assumptions and boundary conditions and material parameters as given by Lam et al. [8] Vacancies were assumed to migrate via the alloying elements with a migration energy of $1.3 \mathrm{eV}$, which is the same as the energy for vacancy migration in pure Fe. However, according to Lam, from the different values of $D_{0}$ measured experimentally (see Ref. [8]), the pre-exponential attempt-frequency factors for $\mathrm{Ni}$, $\mathrm{Cr}$ and $\mathrm{Fe}$ were different. No preferential association of defects with $\mathrm{Fe}, \mathrm{Cr}$ or $\mathrm{Ni}$ atoms is assumed. Segregation of the alloying elements results from the difference in vacancy diffusion coefficients caused only by the inequality of the pre-exponential jump-frequency factors. There is no effect of interstitial fluxes because all the partial diffusion coefficients of interstitials via the three alloying elements are equal.

Results show that enrichment of $\mathrm{Ni}$ and depletion of $\mathrm{Cr}$ and $\mathrm{Fe}$ occur in agreement with the calculations of Lam et al. $[8,21]$. The quantity of interest is the amount of chromium depleted from the grain boundary, or the area inside the $\mathrm{Cr}$ concentration profile. The amount of $\mathrm{Cr}$ depletion for 'corrected' and 'reported' dose rates is given in Table 1 for each experiment. Also given are the values of $\mathrm{Cr}$ depletion at steady state and the doses required to reach steady state. Fig. 5 shows the amount of $\mathrm{Cr}$ depletion as a function of temperature and displacement rate at steady state. Steady state is reached at different dose levels for each experiment. At a given displacement rate, the segregated area peaks at some intermediate temperature and falls off at both higher and lower temperatures. This is due to the dominance of recombination at low temperatures and back diffusion at high temperatures [7]. Also note that the effect of a decreasing displacement rate is to shift the curves to higher maxima at lower temperatures. For a given dose, a lower displacement rate yields lower steady state defect concentrations, reducing the number of defects lost to recombination, and shifting the curve to lower temperatures while increasing the degree of segregation.

Note the change in the calculated values for the amount of $\mathrm{Cr}$ depletion in the four experiments shown in Fig. 5. Since electrons are assumed to be $100 \%$ efficient in producing defects available to affect segregation, there is no change in the segregated area after accounting for efficiency. However, there is a difference with protons, heavy ions and neutrons. The difference is largest for neutrons and smallest for protons. The difference is a function of not only the displacement efficiency, but also the slope of the dose rate curves. Nevertheless, substantial differences result in the expected amounts of grain boundary segregation when the displacement efficiency is taken into account.

Fig. 5 shows the effect of three of the four parameters defining an experiment: particle type, temperature and dose rate. It does not show the effect of dose since this is a steady state result which is achieved at different doses for each of the experiments described in Table 1. Fig. 6 shows the development (vs. dose) of the segregated area, i.e. chromium depletion during irradiation for each of the four experiments described in Table 1. Each particle type generates a pair of curves, the top curve (at large dose) results from use of the corrected displacement rate and the bottom curve from use of the reported displacement rate. A single curve was used for electron irradiation since the efficiency of defect production for electrons was assumed to be $100 \%$. The points on the curves indicate the doses (times) to which these experiments were conducted. The arrows indicate the changes in the measured de-

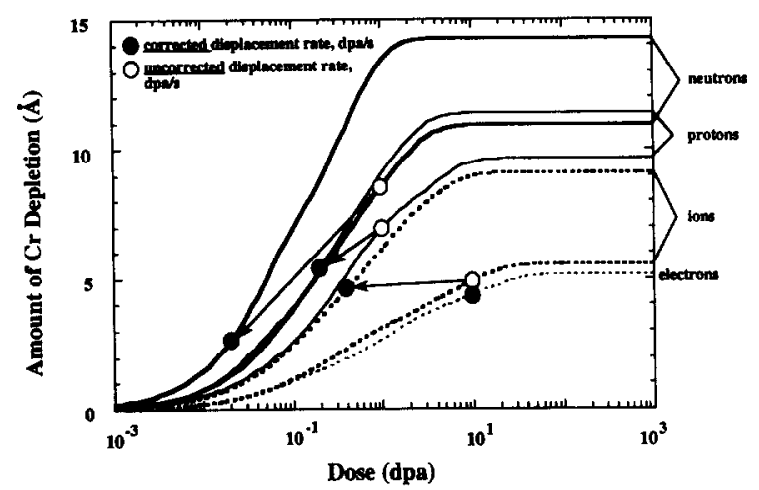

Fig. 6. Amount of chromium depletion as a function of irradiation dose for each particle type. The upper curve (at steady state) in each pair accounts for the particle efficiency while the lower curve is for the reported (uncorrected) dose rate. The symbols refer to the conditions for the experiments described in Table 1. 
pletion when the reported displacement rate and dose are corrected using the efficiency factors in Table 1. In none of the experiments is steady state reached after the reported dose. This is particularly true for electron irradiation where even after $10 \mathrm{dpa}$, the steady state dose is still a factor of 3 away. Even in the case of neutrons, a real dose of $1 \mathrm{dpa}$ (just past the threshold for observation of IASCC) falls on the steep portion of the curve, indicating that the measured amount of segregation is very sensitive to the duration of the experiment.

A final point of importance is the amount of $\mathrm{Cr}$ depletion that would be measured for each of the particle types after the stated duration of each experiment. Fig. 6 shows that for these four experiments, the amount can vary by almost a factor of 3 between various particle types. This is essentially an effect of the rate dependence on the amount of segregation. The curves in Fig. 6 also show the interplay between rate and efficiency for a fixed amount of segregation. Low efficiencies or low displacement rates will produce greater amounts of segregation after a fixed dose than higher efficiencies or higher displacement rates. This trade-off works against experimenters using ion irradiation to study neutron damage. Generally, the efficiency is better for lighter ions, and due to the nature of the instrumentation (accelerators, HVFM microscope), damage rates are generally much higher.

Fig. 7 summarizes the resulting discrepancies between determination of the amount of segregation using the 'reported' dpa rates and doses vs. 'corrected' values which account for the efficiency of producing freely migrating defects available for affecting segregation. As expected, the difference is generally largest for the particle type with the greatest correction to the dpa rate. However, the difference is strongly dependent on

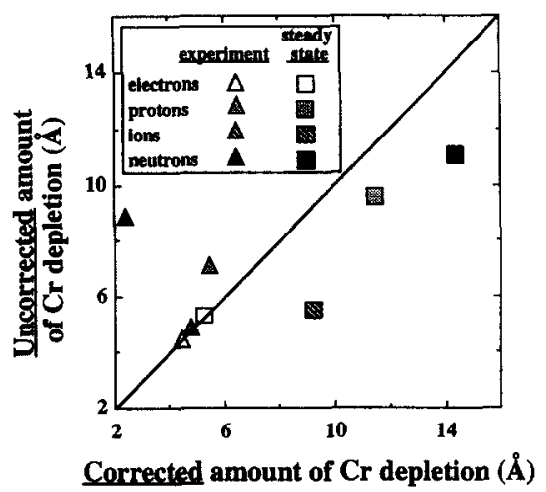

Fig. 7. Comparison of the amount of chromium depletion accounting for particle efficiency (corrected amount of $\mathbf{C r}$ depletion) and that using the reported (uncorrected) values of dose and dose rate (uncorrected amount of $\mathrm{Cr}$ depletion) for the experiments given in Table 1 and at steady state. the dose to which the experiment is carried. In fact, ion irradiation experiments near $10 \mathrm{dpa}(0.4$ 'corrected' dpa) will show virtually no discrepancy due to the cross-over of the segregation curves at that time.

These examples also illustrate the methodology for determining equivalence between grain boundary composition for irradiation with different particle types. In practice, the method may be used either to determine the irradiation conditions which achieve equivalence a priori, or to determine the relative amounts of grain boundary segregation 'expected' given the parameters defining the experiment.

\subsubsection{Measuring radiation-induced segregation}

Radiation-induced segregation near grain boundaries is measured using two principle methods - energy dispersive $\mathrm{X}$-ray analysis in scanning transmission electron microscopy (STEM-EDS) and scanning Auger microanalysis (SAM). In STEM-EDS, the electron beam is focused to a spot of order $2 \mathrm{~nm}$ and used as a probe for the generation of $X$-rays from the volume of the foil through which it passes. The $\mathrm{X}$-ray intensities can be used to determine the composition of the material in the sample volume. The composition profile of an element near a grain boundary is then determined by stepping the electron beam probe across the grain boundary and converting the X-ray signal intensity profile to a composition profile. STEM-EDS is a tricky technique which requires a fine probe size $(\leqslant 2 \mathrm{~nm})$, a grain boundary which can be accurately aligned with the probe direction and a sampling region in which the foil thickness is less than $100 \mathrm{~nm}$ and is accurately known. Even so, the finite volume of the electron beam probe and the broadening of the initial probe size inside the sample due to electron scattering limit the spatial resolution of the technique to 2-3 nm at best.

An alternative technique is Auger electron spectroscopy (AES) which involves the identification and quantitative determination of elements from the energy of the Auger electrons emitted from the interaction of an electron beam with a surface. This technique requires a different sample geometry. In AES, the composition of a surface is determined by directing the electron beam normal to that surface. As such, in order to investigate grain boundary compositions, the sample must be fractured along the grain boundaries. This is usually accomplished in stainless steels by cathodic charging with hydrogen and straining in situ in the Auger vacuum chamber. As such, unless sputter depth profiling can be accomplished on a faceted surface (generally very difficult), the information on sample composition is limited to the grain boundary plane itself. In AES, the depth resolution rather than the spatial resolution is a concern. The nominally $10 \mathrm{keV}$ clectrons penetrate and produce Augcr electrons over several-nm below the surface. However, those collected 
by the cylindrical mirror analyzer only come from a depth corresponding to the escape depth of the Auger electrons. Therefore, the accuracy of the measurement is a function of the escape depth of the Auger electrons of interest (i.e. $0.3-1 \mathrm{~nm}$ ). Additional practical considerations influence measurements such as the contamination of the surface with $\mathrm{C}$ and $\mathrm{O}$ from the vacuum, the uncertainty in the location of the fracture along the grain boundary plane and the possibility of erring on identification of grain boundary facets due to the occurrence of mixed mode fracture. These two tcchniques provide all the information we have on RIS at grain boundaries.

\subsubsection{Comparison of model and experiment}

Chromium concentration profiles at the grain boundaries, determined from code calculations, are shown in Figs. 8-10 and compare the measured data taken using STEM and AES to the model calculations for several irradiations. Fig. 8 presents results from proton irradiation, Fig. 9 from neutron irradiations and Fig. 10 from heavy ion irradiations. The irradiation conditions for protons and ions are identical to those in Table 1 with the exception of the final dose of the ion irradiation. The neutron irradiations were all done at $288^{\circ} \mathrm{C}$ but doses and dose rates vary according to the reactor in which they were done. Neutron irradiations were uncontrolled in that the reported grain boundary composition profiles were taken from core components and not, controlled environment test capsules. Each graph shows the experimental data, the code prediction for the nominal conditions and that accounting for the particle efficiency.

Fig. 8 shows the comparison of STEM-EDS measurements and code calculations for three controlled

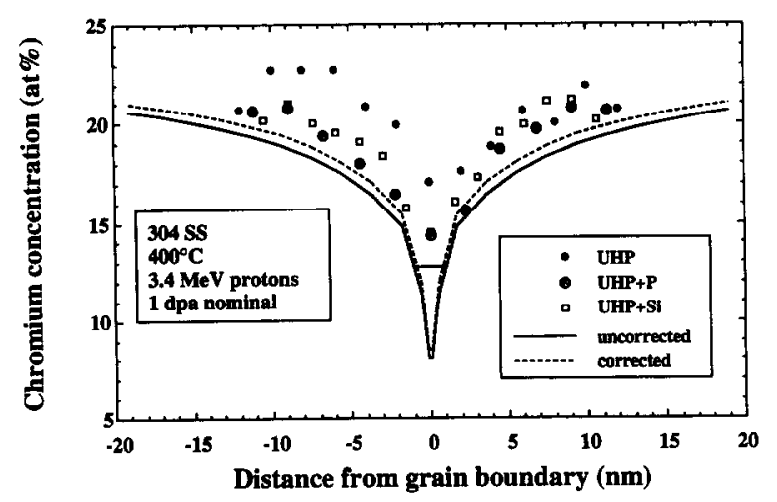

Fig. 8. Comparison of experiment and model results of the chromium depletion profile in stainless steel following irradiation of alloys $\mathrm{UHP}, \mathrm{UHP}+\mathrm{P}$ and $\mathrm{UHP}+\mathrm{Si}$ with $3.4 \mathrm{MeV}$ protons at $400^{\circ} \mathrm{C}$ to $1 \mathrm{dpa}$. The horizontal bar represents the diameter of the electron probe in STEM-EDS measurements. Dashed and solid lines are the model results corrected and uncorrected, respectively, for the particle efficiency. purity alloys irradiated with $3.4 \mathrm{MeV}$ protons at $400^{\circ} \mathrm{C}$ to 1 dpa (nominal) [22]. The dotted line is the 'corrected' $\mathrm{Cr}$ profile determined using the efficiency-corrected dose rate, and the solid line is the uncorrected profile. Fig. 8(a) for the high-purity alloy shows reasonably good agreement between code and experiment in shape, but not in magnitude. From both the grain boundary value and the FWHM of the profile, it is evident that the code calculations overestimate the extent of chromium depletion. That this is a deficiency in the code as opposed to the experimental measurements is indicated by the excellent agreement between STEM-EDS and AES on the value of $\mathrm{Cr}$ at the grain boundary. Note that the calculated profiles match the experimental profiles much better in the UHP $+\mathbf{P}$ and UHP + Si alloys. These alloys are essentially the same as the UHP alloy except that they are doped with $\mathbf{P}$ and $\mathrm{Si}$, respectively. In both cases, the shape and magnitude of the experimental and calculated results match very well beyond $2 \mathrm{~nm}$ from the grain boundary. The lack of agreement within $2 \mathrm{~nm}$ of the grain boundary is a consistent problem. In part, it may be due to the lack of spatial resolution in STEM-EDS and depth resolution in AES. However, the magnitude of the discrepancy is too large to be accounted for by resolution. The better agreement between experiment and theory for the doped alloys is not unexpected. Evidence exists to show that the addition of $\mathrm{P}$ and $\mathrm{Si}$ to $\mathrm{Fe}-\mathrm{Cr}-\mathrm{Ni}$ increases the effective vacancy diffusion coefficient, thus leading to a broader and deeper profile under irradiation [23]. An additional factor which may affect the grain boundary value is the increase in the vacancy formation energy by the addition of solutes which decrease the equilibrium vacancy concentration at the boundary and result in an increased vacancy flux to the boundary [24].

Figs. 9(a)-(c) show STEM-EDS results compared to code calculations for a high-purity alloy irradiated to increasing doses. Figs. 9(d) and (e) show the comparison for commercial purity alloys; the former irradiated in an LWR [25] and the latter in a test reactor (ATR) [26]. Code calculations were renormalized to match the measured chromium levels at $20 \mathrm{~nm}$ from the grain boundary. Inspection of Fig. 9 shows that the code significantly underpredicts the grain boundary composition in all the neutron irradiated cases. This is in agreement with results of Norris et al. [27] using Perks model [10] in a comparison with neutron irradiated $20 \% \mathrm{Cr} / 25 \% \mathrm{Ni} / \mathrm{Nb}$ stabilized steel used as fuel pin cladding in the Advanced Gas-Cooled Reactor. It also shows, that the effect of the particle efficiency can be very significant. In particular, except for the profile being off center, Fig. $9(d)$ shows rather good agreement between experiment and corrected profile beyond $2 \mathrm{~nm}$ from the grain boundary. Similarly, the ATR data, Fig. 9(e), also shows better agreement be- 
yond $2 \mathrm{~nm}$. Considering the purity of these samples, the results support those found in the proton irradiated UHP alloys, showing that impurities increase the amount of $\mathrm{Cr}$ segregation at the grain boundary.

Fig. 10 shows the comparison with between model and experiment for the UHP alloy of Fig. 8 irradiated with $5 \mathrm{MeV} \mathrm{Ni}^{2+}$ ions to a dose of $5 \mathrm{dpa}$ at $500^{\circ} \mathrm{C}$. This result is somewhat peculiar in that it is the only case in which the experimental measurements produce a broader profile than the model.
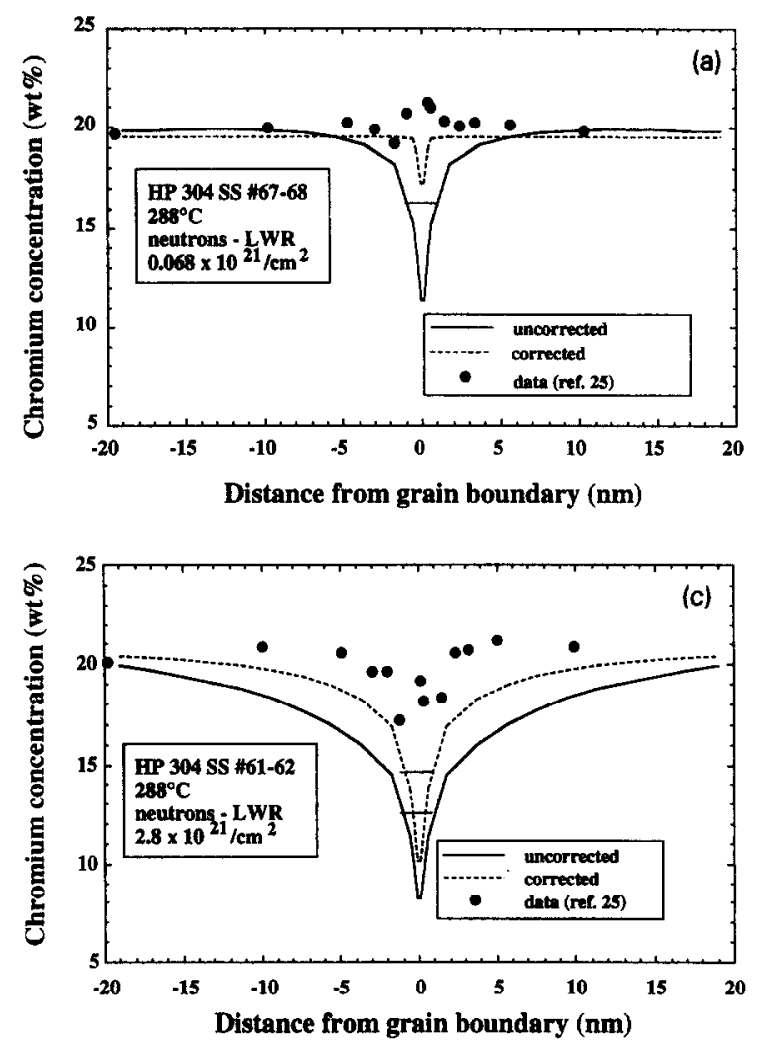

\subsubsection{Relation between segregation and IG cracking}

It is well known that the depletion of chromium at grain boundaries in austenitic alloys, due to thermal sensitization is a direct cause of enhanced IGSCC, and this is treated in detail in the preceding paper by Bruemmer and Was [28]. It is therefore reasonable to expect that $\mathrm{Cr}$ depletion arising from irradiation would cause a similar effect. The main difference between thermal and radiation-induced $\mathrm{Cr}$ depletion is the width of the profile. However, as shown by Bruemmer [29],
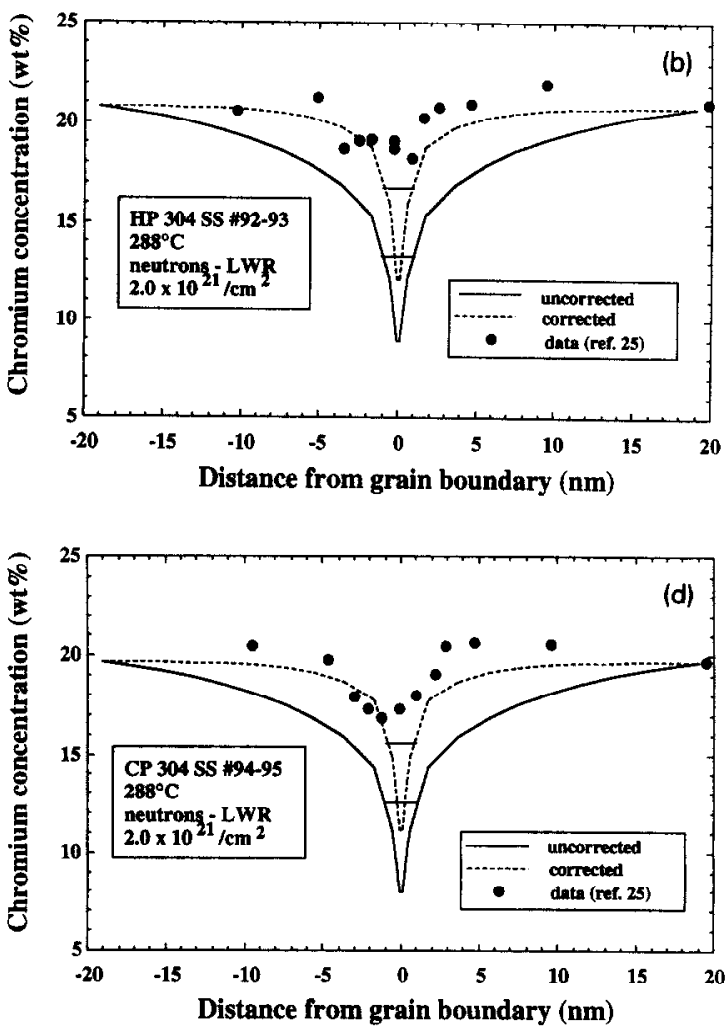

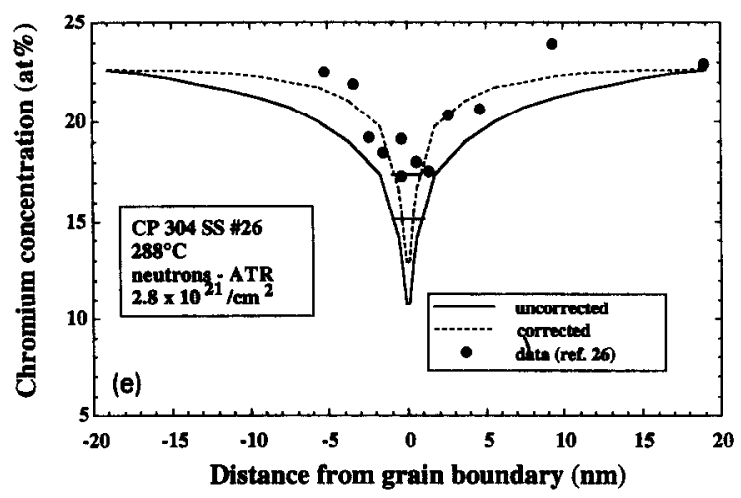

Fig. 9. Comparison of experiment and model results of the chromium depletion profile in stainless steel following neutron irradiation at $288^{\circ} \mathrm{C}$ at various doses with $E \geqslant 1 \mathrm{MeV}$ (a) $\mathrm{HP}$ alloy, $0.068 \times 10^{21} \mathrm{n} / \mathrm{cm}^{2}$ in LWR (b) HP alloy, $2.0 \times 10^{21} \mathrm{n} / \mathrm{cm}^{2}$ in LWR, (c) HP alloy, $2.8 \times 10^{21} \mathrm{n} / \mathrm{cm}^{2}$ in LWR, (d) CP alloy, $2.8 \times 10^{21} \mathrm{n} / \mathrm{cm}^{2}$ in LWR, and (e) CP alloy, $2.8 \times 10^{21} \mathrm{n} / \mathrm{cm}^{2}$ in ATR. The horizontal bar represents the diameter of the electron probe in STEM-EDS measurements (data from Refs. [25,26]). 


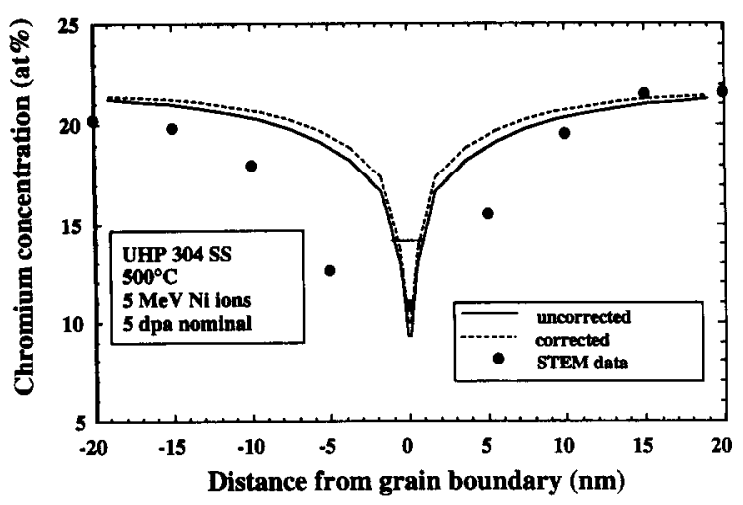

Fig. 10. Comparison of experiment and model results of the chromium depletion profile in the UHP alloy following irradiation with $5 \mathrm{MeV} \mathrm{Ni}^{2+}$ at $500^{\circ} \mathrm{C}$ to $5 \mathrm{dpa}$. The horizontal bar represents the diameter of the electron probe in STEM-EDS measurements.

IGSCC is much more dependent on the magnitude of $\mathrm{Cr}$ depletion than on the width of the profile. Slow strain rate tests in aerated high-temperature water revealed no significant effect of $\mathrm{Cr}$ depletion width when it exceeded $4 \mathrm{~nm}$. Thus, correlations between $\mathrm{Cr}$ depletion and IASCC are expected. Such a cause and effect is not so clearly established in the case of segregated impurities. Although $\mathrm{Si}, \mathrm{P}, \mathrm{S}, \mathrm{B}, \mathrm{N}$ and other elements have been implicated in the IASCC process, there is little evidence in the literature that these elements enhance SCC in water at high temperatures. Of these impurity elements, only $\mathrm{Si}$ and $\mathrm{P}$ have been conclusively shown to segregate under irradiation. The correlation between IGSCC and grain boundary composition is discussed in more detail in Section 3. However, much remains to be learned about how grain boundary segregation affects IGSCC.

\subsection{Radiation effects on materials}

\subsubsection{Microstructure}

Although there has been an emphasis on microchemical changes, the effect of radiation on the microstructure may play an important role, principally through hardening. Zinkle and Singh [30] have recently reviewed the subject of displacement damage and defect production and emphasize that the resulting microstructure is strongly dependent on (1) the proportion of defects produced heterogeneously in the form of vacancy and interstitial clusters, (2) the bias for absorption of mobile interstitial clusters and freely migrating interstitials at sinks, (3) the asymmetry in the production of freely migrating fractions of interstitials and vancancies due to the differing fractions of vacancies and interstitials in clustered or isolated forms, and (4) vacancy evaporation from clusters. Hence, the evo- lution of the microstructure during irradiation is a complex process depending on a number of processes.

The existing data on the radiation damage microstructure has been recently analyzed by Maziasz and McHargue [31], who show that under LWR conditions $\left(T<350^{\circ} \mathrm{C}\right.$, dpa between 0.5 and 5 , and a LWR neutron spectrum) is rather sparse as the great majority of the data base consists of fast reactor data taken at higher temperatures $\left(400-700^{\circ} \mathrm{C}\right)$, high fluences $(>5$ dpa) and fast reactor spectra. Available data suggest that the primary form of radiation damage in austenitic stainless steels at $300^{\circ} \mathrm{C}$ is interstitial Frank loops (10$20 \mathrm{~nm}$ diameter) and black dot damage (2-3 nm diameter) at densities of order $10^{22} \mathrm{~m}^{-3}$. Higher temperatures result in a lower loop density and cause the growth of loops and the development of a dislocation network structure. As the fluence increases, at any temperature, Frank loops tend to unfault and form a dislocation network. The network becomes part of the total dislocation density which increases with increasing fluence until saturation. The total dislocation density reflects the temperature and fluence dependence of loop nucleation and growth up to the point of unfaulting. The dislocation density thus represents a dynamic balance between loop nucleation, growth, and unfaulting, resulting in generation of a dislocation network and mutual annihilation of dislocation segments, eliminating the dislocation network.

\subsubsection{Radiation-induced hardening}

The formation of a secondary damage structure will affect the mechanical properties of the alloy through interactions with dislocations. Post-irradiation data for neutron irradiation of 300 series austenitic alloys at $300^{\circ} \mathrm{C}$ show that with increasing dose, the yield strength increases, and ductility and fracture toughness decrease. The increase in yield strength is large and rapid, such that by a dose of $4 \mathrm{dpa}$, the yield strength is nearing saturation at a level 4 to 6 times the unirradiated value [33]. Uniform elongation drops from nearly $30 \%$ in solution annealed material to $<2 \%$ by $4 \mathrm{dpa}$, Fig. 11. Similarly, fracture toughness drops by a factor of 2 to 3 by the same dose level, Fig. 12. As such, the irradiated alloy is significantly 'embrittled' by irradiation in the $300^{\circ} \mathrm{C}$ range at doses less than $5 \mathrm{dpa}$.

Post-irradiation tensile testing at $300^{\circ} \mathrm{C}$ often results in plastic instability caused by dislocation channeling in which deformation is confined to submicron shear bands with the matrix undergoing relatively little deformation. Initially homogeneous deformation can be shifted to heterogeneous deformation when a dislocation clears a slip plane of radiation damage debris. This provides an easier path for subsequent dislocation motion and slip becomes confined to a narrow band of slip planes which are free from clustered defects. This 'dislocation channeling' results in intense shear bands 
and can cause localized necking and a sharp reduction in uniform elongation. These have been observed in high-purity 304 alloys at doses as low as 1 dpa [24]. At high fluences, a distinct fracture mode is found, transgranular channel fracture, in which fracture occurs along the deformation channels resulting in flat, crystallographic facets. However, channel fracture is confined to fluences $>5 \times 10^{26} \mathrm{n} / \mathrm{m}^{2}$ ( $20 \mathrm{dpa}$ ), well beyond that required for saturation of the yield stress, and to temperatures in the range $250-450^{\circ} \mathrm{C}$ [35]. This encompasses the temperature range of interest, but the dose is far greater than the 'threshold' dose for the onset of IASCC. Channel fracture has been observed in microstructures which contain a substantial void population, although it is not known whether the pres-

(a)

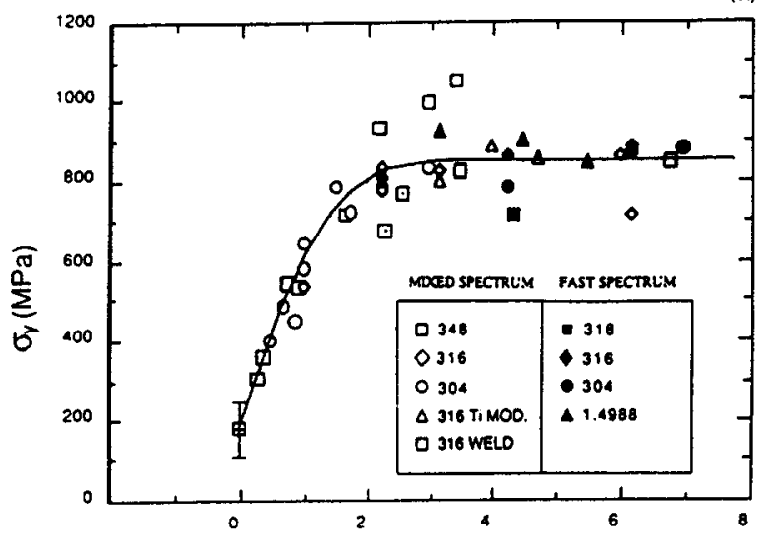

(b)

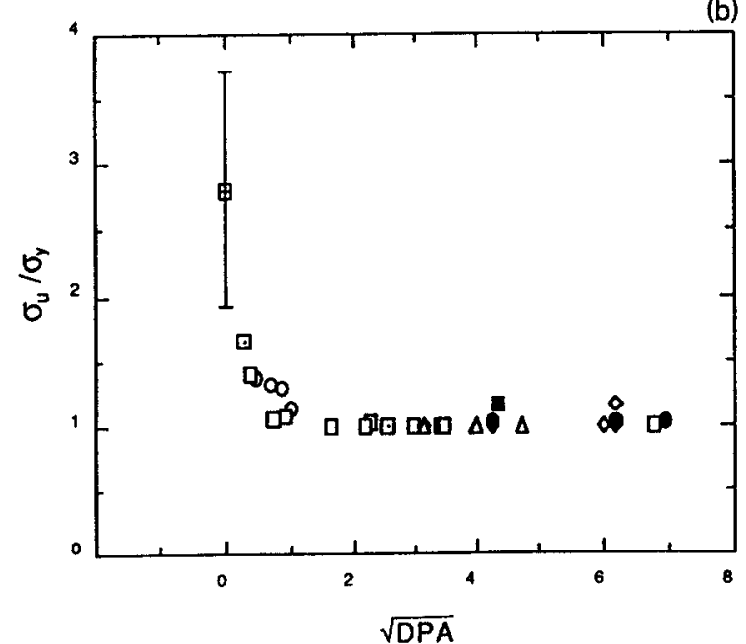

Fig. 11. (a) The yield stress and (b) the uniform elongation as a function of the square root of the dpa for 300-series austenitic stainless steels irradiated and tested at about $300^{\circ} \mathrm{C}$. The square symbol with the error bars are the average and approximate ranges of the unirradiated yield stress (a) or uniform elongation (b). The other symbols are defined in the legend which is common to both (a) and (b) (from Ref. [32]).

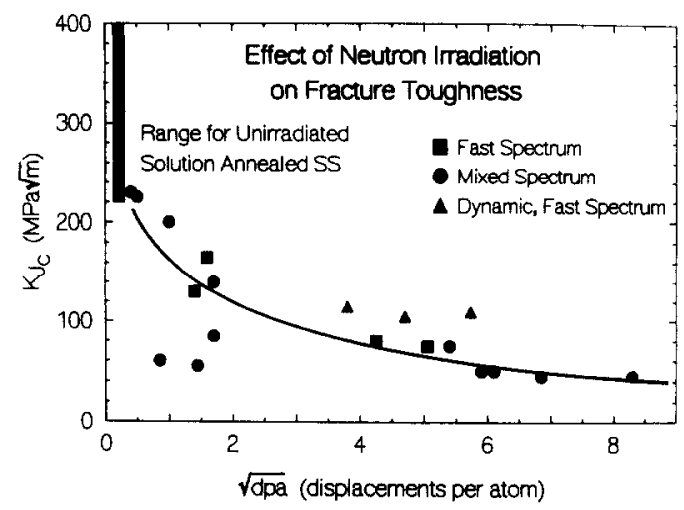

Fig. 12. Effect of fast neutron fluence under LWR conditions on the fracture toughness at $288^{\circ} \mathrm{C}$ of types 304 and $304 \mathrm{~L}$ stainless steel (from Refs. [33,34]).

ence of voids is necessary for this fracture mode to occur.

It has been recognized that low-temperature fracture in unirradiated alloys probably initiates in regions of high stress caused by inhomogeneous deformation, such as precipitate-matrix interfaces. Irradiation could lead to fracture initiation at lower strains because of strain localization in the deformation bands. At higher temperatures where grain boundaries tend to be weaker than the matrix, the intersection of channels with the boundary may initiate grain boundary cracks through the formation of wedge cracks or by initiating grain boundary sliding. With respect to the IASCC problem then, the localization of deformation into dislocation channels could contribute to grain boundary fracture by a combination of factors: the localization of deformation at the channel-grain boundary intersection, the weakening of grain boundaries relative to matrix by radiation hardening of the matrix and the weakening of grain boundaries due to composition changes such as impurity segregation or $\mathrm{Cr}$ depletion which would increase susceptibility to SCC.

\subsubsection{Crack growth}

Once initiated, crack growth will depend on both the material properties and the environment. Andresen has formulated a predictive model for IASCC in which the average crack velocity, $V_{\mathrm{T}}$ is represented by $V_{\mathrm{T}}=f(n)\left(\epsilon_{\mathrm{ct}}\right)^{n}$, where the crack tip strain rate, $\epsilon_{\mathrm{ct}}$ embodies the mechanical contributions and $n$ encompasses the effects of the environment and materials chemistries on environmentally assisted crack growth [5,6,36-38]. For unagressive material and environment combinations, the relationship between growth rate and crack tip strain rate tends to become linear (i.e., $n \rightarrow 1$ and $\left.V_{\mathrm{T}}=A \epsilon_{\mathrm{ct}}\right)$. The crack tip strain rate can generally be expressed in terms of the material depen- 


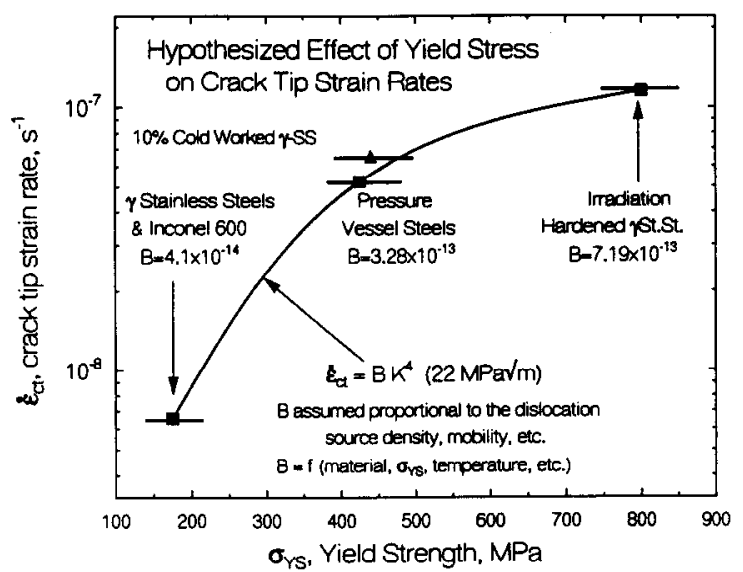

Fig. 13. Proposed effect on $288^{\circ} \mathrm{C}$ crack tip strain rate of yield strength, whether altered by alloying or cold work. Based on formulations for annealed (or sensitized) stainless steel and low alloy steel, which are also consistent with the effects of cold work and perhaps irradiation hardening in stainless steel (from Ref. [4]).

dence, $B$ and the stress dependence, $K$ as $\epsilon_{\mathrm{ct}}=B K^{4}$. Since $B$ is assumed to vary linearly with yield strength, then an increase in yield strength duc to irradiation to 4 dpa should increase $B$ by a factor of $6-8$, which translates into a factor of 6-8 increase in the crack growth rate, in reasonable agreement with observations, Fig. 13.

\subsubsection{Radiation creep}

The situation may be quite different where deformation is occurring during irradiation when segrega-

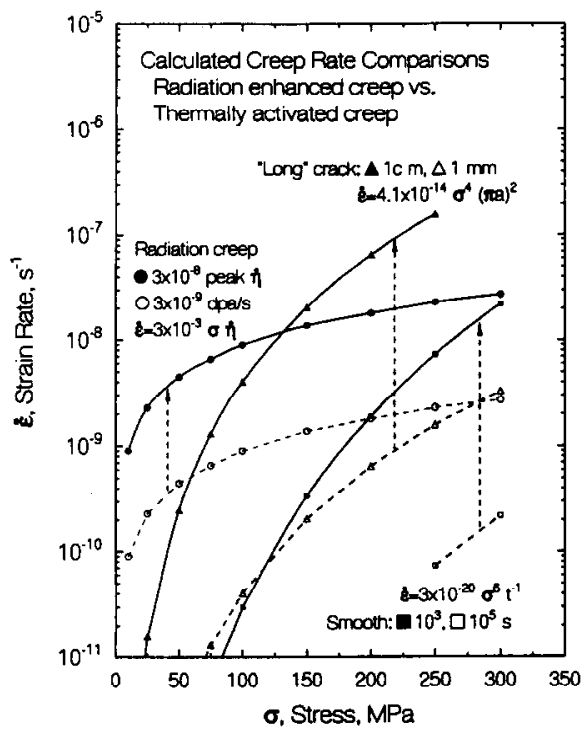

Fig. 14. Comparison of calculated creep rates from radiation enhanced creep, and thermally activated creep on smooth and defected specimens (from Ref. [4]). tion, hardening and irradiation creep are all occurring simultaneously. The effect of radiation creep may be either beneficial, by load relaxation under constant displacement conditions, or harmful, under constant load conditions where irradiation creep may contribute to enhanced cracking. At low temperatures, transient creep occurs due to the climb and pinning of the dislocation network in the solid. Steady state creep can be due to several mechanisms. The creep rate is generally found to be proportional to the stress and the displacement rate. As such, creep rates at low temperatures can be significantly enhanced over thermal creep. In fact, for the conditions typical of LWR core materials, irradiation creep is expected to be orders of magnitude higher than thermal creep, Fig. 14 [39]. In fact, radiation creep compliance also appears to be a minimum at temperatures near $300^{\circ} \mathrm{C}$. If creep deformation is confined to localized slip bands, then it may contribute to the high local stresses at the intersection of slip bands and grain boundaries and assist IG crack initiation.

\subsection{Radiation effects on water chemistry and corrosion potential}

Ionizing radiation causes water to break down into various oxidizing and reducing species (e.g., $\mathrm{H}_{2}, \mathrm{H}$; $\mathrm{H}_{2} \mathrm{O}_{2}, \mathrm{OH} ; \mathrm{H}^{\circ} \mathrm{O}_{2}, \mathrm{e}_{\mathrm{aq}}^{-}$). The $G$ value describes the instantaneous yield of each species per $100 \mathrm{eV}$ absorbed by water, and is sensitive to the energy spectrum. The concentration of each species varies over time from decomposition and recombination, which are strongly influenced by radiation flux (esp. gamma), ionic species, dissolved gases, temperature, etc. In LWRs, the $G$ values for most species are within a factor of approximately 3 for fast neutron vs. gamma radiation. However, fast neutrons deposit energy much more rapidly than gamma radiation, as quantified by the mean linear energy transfer (LET) which is 40 and $0.01 \mathrm{eV} / \mathrm{nm}$, respectively) [4]. Additionally, the peak neutron flux in LWRs in also higher than the gamma flux. Moderate gamma levels, such as exist in the downcomer annulus of a BWR, actually promote recombination of hydrogen and various oxidants [4]. Thermal neutrons and beta particles play an insignificant role in LWR radiolysis.

While the formation of oxidants and reductants represents the origin of radiation effects on water chemistry, their influence is best integrated and understood in terms of changes in corrosion potential, which controls the thermodynamics and kinetics of electrochemical reactions. The corrosion potential is a mixed potential on the surface of a metal involving a balance of anodic and cathodic reactions. The electrochemical potential, $\phi$, of each reaction is logarithmically dependent on the local oxidant, reductant, and ionic concen- 
trations via the Nernst relationship, $\phi=\phi_{0}+(R T / n F)$ In[products/reactants]. Thus, increases in concentration of various species by many orders of magnitude from radiolysis may have comparatively small effects on the corrosion potential in high-temperature water. This is indeed observed (Fig. 15(a)) until the oxidant level decreases to the point where one reaction (e.g., oxygen reduction) becomes limited by mass transport to the surface; at this point a rapid, sigmoidal decrease in corrosion potential is observed, toward the thermodynamic value of approximately $-0.5 \mathrm{~V}_{\text {she }}$ associated with the hydrogen-water reaction.
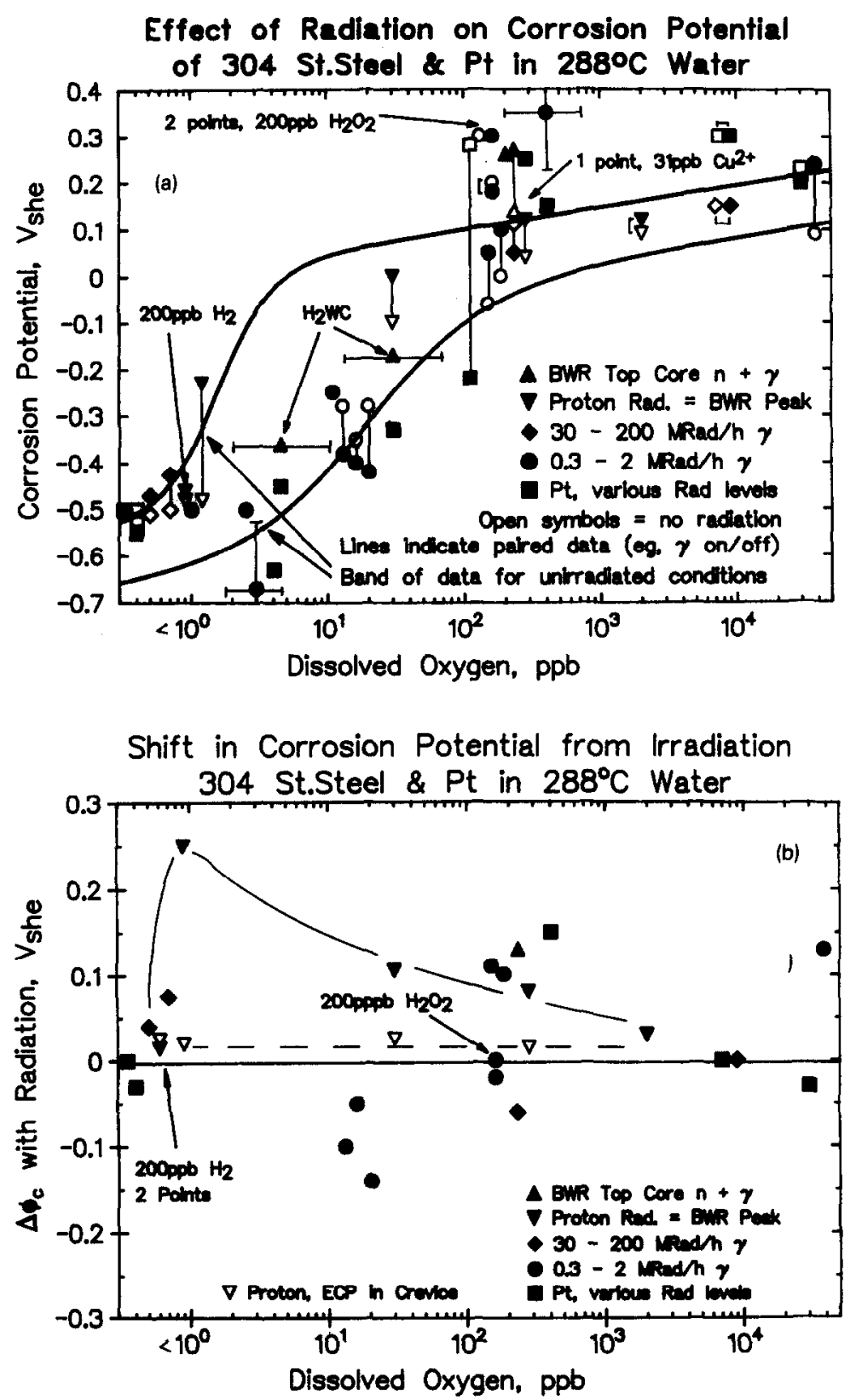

Fig. 15. (a) Effect of radiation on the corrosion potential of type-304 stainless steel in $288^{\circ} \mathrm{C}$ water. The curves denote the range of typical values in the unirradiated corrosion potential data [4]. (b) Effect of radiation on the shift in corrosion potential from the value under unirradiated conditions for type-304 stainless steel in $288^{\circ} \mathrm{C}$ water. With the exception of the BWR measurements, all data were obtained in controlled radiation on/off experiments. Curves in (b) show the trends in the proton irradiated data, where the effects of radiation (on/off and over a range of fluxes) were evaluated for a variety of dissolved $\mathrm{O}_{2}$ and $\mathrm{H}_{2}$ concentrations under otherwise identical conditions (from Ref. [4]). 
Fig. 15(a) shows the relationship between dissolved oxygen and corrosion potential in high-temperature water as a function of radiation type and flux. The connected points represent data obtained in controlled, radiation on /off experiments, and are plotted in Fig. 15(b) in terms of a radiation-induced shift in potential. The curves in Fig. 15(a) represent the scatter band for the data obtained under unirradiated conditions.

Fig. 15 shows that little, if any, elevation in corrosion potential results from irradiation sources which do not include neutrons or simulate their contribution by, e.g., using high-energy protons [4]. Some studies using gamma radiation showed a significant decrease in corrosion potential, which is consistent with enhanced recombination in the downcomer region of BWRs [4]. In instances where neutrons or protons have been used, a consistent, significant elevation in corrosion potential is observed which is more pronounced in high-temperature water containing low dissolved oxygen concentrations and no dissolved hydrogen (Fig. $15(\mathrm{~b})$ ), where shifts of over $+0.25 \mathrm{~V}$ occur. At higher inlet oxygen concentrations (e.g., approximately 200 $\mathrm{ppb}$ ), the data still show a significant shift (typically $+0.1-0.15 \mathrm{~V}$ ) in corrosion potential for radiation conditions representative of peak LWR core fluxes (Fig. 15(b)).

Within cracks and crevices it has been postulated that radiation could elevate the corrosion potential above that at the crack mouth. Under unirradiated conditions, measurements in high-temperature water in artificial crevices (e.g., tubing), at the tip of growing cracks, and of short crack growth behavior [4] show that the corrosion potential remains low, approximately $-0.5 \pm 0.1 \mathrm{~V}_{\text {she }}$ in $288^{\circ} \mathrm{C}$ pure water, independent of the oxygen concentration externally. Similar measurements in crevices under irradiated conditions [4] show that the shift in corrosion potential is < $0.05 \mathrm{~V}$.

The effects of corrosion potential on IASCC have been studied $[4,40-43]$ on pre-irradiated type-304 stainless steel using slow strain rate testing (SSRT) in $288^{\circ} \mathrm{C}$ water with additions of oxygen and/or hydrogen peroxide to elevate the corrosion potential to simulate the effect of radiation. Tests by Jacobs et al. [40] on stainless steel irradiated to $\sim 3 \times 10^{21} \mathrm{n} / \mathrm{cm}^{2}$ showed a strong effect of dissolved oxygen (and, by inference, corrosion potential) on IASCC.

Asano et al. [41] used a similar testing approach on pre-irradiated types 304 and 316 stainless steel, and observed a similar dependence of IASCC on corrosion potential (Fig. 1). The Asano data is, however, offset to the right (to higher fluences) from the Jacobs data; this difference is consistent with the measured enrichment in grain boundary $\mathrm{Cr}$ in the initial, solution annealed condition. This initial enrichment required $\sim 1 \times 10^{21}$ $\mathrm{n} / \mathrm{cm}^{2}$ before the grain boundary $\mathrm{Cr}$ level decreased to the matrix level.

Ljungberg [43] also tested a variety of pre-irradiated materials by slow strain rate, Fig. 16, and observed decreasing average crack growth rates with decreasing corrosion potential. Finally, in-situ, fracture mechanics, crack growth rate data from furnace sensitized type-304 stainless steel was obtained at Nine Mile Point Unit 1

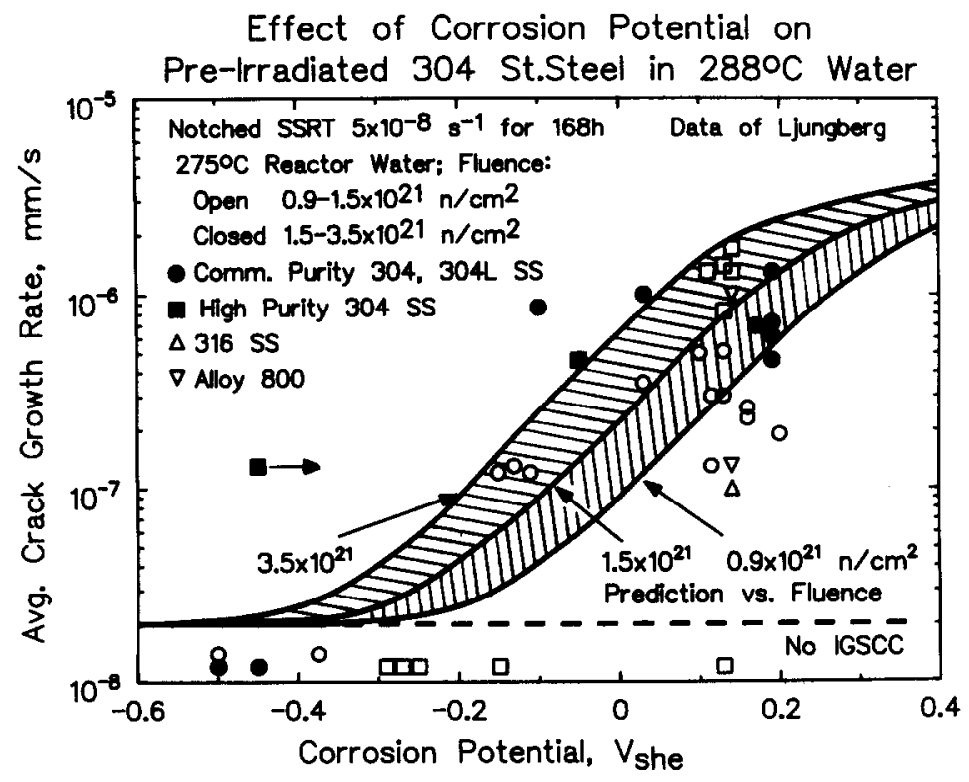

Fig. 16. Comparison of predicted and observed crack growth rates for stainless steels irradiated in a $\mathrm{BWR}$ at $288^{\circ} \mathrm{C}$ to various fluences. Notched tensile specimens were tested by Ljungberg [43] at a slow strain rate in $288^{\circ} \mathrm{C}$ pure water (from Ref. [4]). 


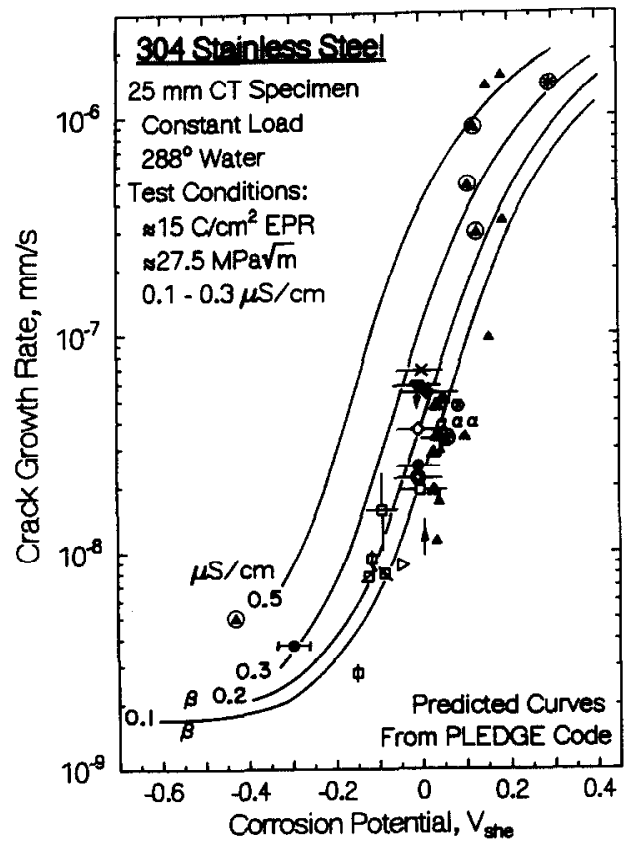

Fig. 17. Observed and predicted crack growth rate versus corrosion potential for furnace sensitized type-304 stainless steel at a constant $K$ of $\sim 27.5 \mathrm{MPa} \sqrt{\mathrm{m}}$. The observed data were obtained in water of conductivity between 0.1 and 0.3 $\mu \mathrm{S} / \mathrm{cm}$. The circled points above $0.1 \mathrm{~V}_{\text {she }}$ (and at $-0.42 \mathrm{~V}_{\text {she }}$ ) were obtained in-core in a BWR or under proton irradiation simulating BWR core exposure (from Ref. [4]).

BWR, and showed that the higher corrosion potentials measured in-core vs. in the recirculation piping induced significantly higher measured crack growth rates [4]. These data are compared with other irradiated and unirradiated data in Fig. 17 based on simultaneous measurements of corrosion potential and crack growth rate in fracture mechanics specimens; the accompanying curves represent model predictions.

\section{Correlations between mechanism and experiment}

\subsection{Fluence effects on IGSCC}

The existence of a critical fluence for IGSCC susceptibility is an essential part of the definition of IASCC. The results of Jacobs et al. [40] and Kodama et al. [42] on BWR-irradiated, commercial purity (CP) 304 SSs were presented in Fig. 1 using the \%IG cracking in the SSR tests (strain rate of $3.7 \times 10^{-7} / \mathrm{s}, 32 \mathrm{ppm} \mathrm{O}_{2}$ ) to gage material susceptibility. A difference of about 4 times was seen in the critical fluence for cracking. These data are replotted in Fig. 18 along with results from several other sources [23,44-47]. Plotting fluence on a linear scale (as compared to the more traditional semilog plot in Fig. 1) is done to expand the data set and allow more direct comparison of SCC to other variables examined in following sections.

The SSR test results of Chung et al. [45] indicated susceptibility to IGSCC at a much lower fluence $(<0.2$ $\times 10^{20} \mathrm{n} / \mathrm{cm}^{2}$ ) for high-purity (HP) 304 SS absorber tube material. Although only three fluence levels were tested, a similar trend in cracking with increasing fluence is seen, but shifted to a lower fluence. The increased susceptibilty is surprising since SSR tests were conducted in a less aggressive environment $(0.3$ ppm $\mathrm{O}_{2}$ ). Identical SSR tests on an irradiated CP 304 SS absorber tube by Chung reveal a cracking response between that for Jacobs and Kodama in Fig. 18. A second CP 304 SS (specimens removed from a controlblade sheath), also examined by Chung, revealed very little IGSCC even at fluences up to $2.5 \times 10^{21} \mathrm{n} / \mathrm{cm}^{2}$. Consistent with this heat-to-heat variability is the CP 304 SS data of Clarke and Jacobs [47] and of Jacobs et al. [23] showing isolated samples resistant to IGSCC at fluences above $2 \times 10^{21} \mathrm{n} / \mathrm{cm}^{2}$ while similar specimens failed by nearly $100 \%$ IGSCC. The comparison between the data of Kodama and that of Jacohs for 316 heats also shows an apparent difference in susceptibility. Differences in IGSCC suggest that the 'critical' fluence for susceptibility may vary by more than an order of magnitude among stainless steel heats.

\subsection{Radiation hardening and effects on IGSCC}

Although direct comparisons have not been made between radiation-induced microstructural evolution and IGSCC, yield strength changes with fluence are related to the evolving defect microstructure as discussed in Section 2.2. Yield strength measurements reported by various researchers $[23,40-42,44-48]$ for various neutron-irradiated austenitic stainless steels as

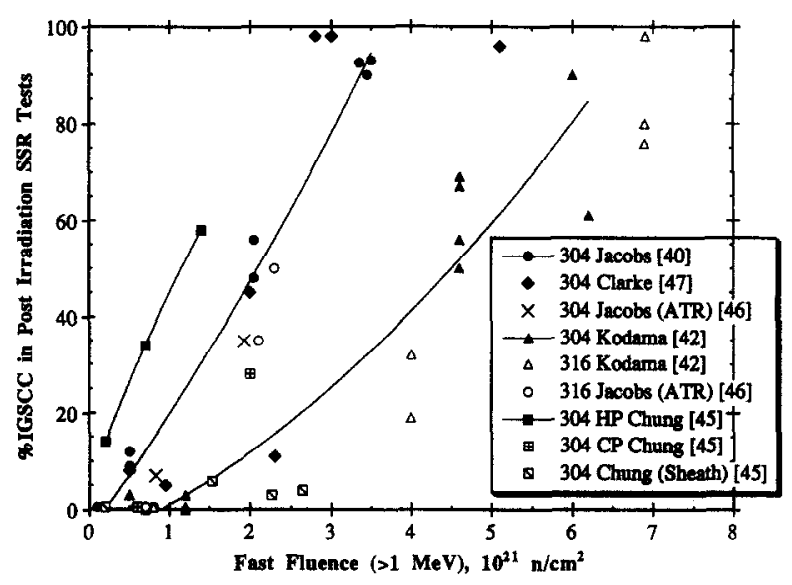

Fig. 18. Summary of reported data for IGSCC susceptibility of irradiated stainless steels as a function of fast neutron fluence. 


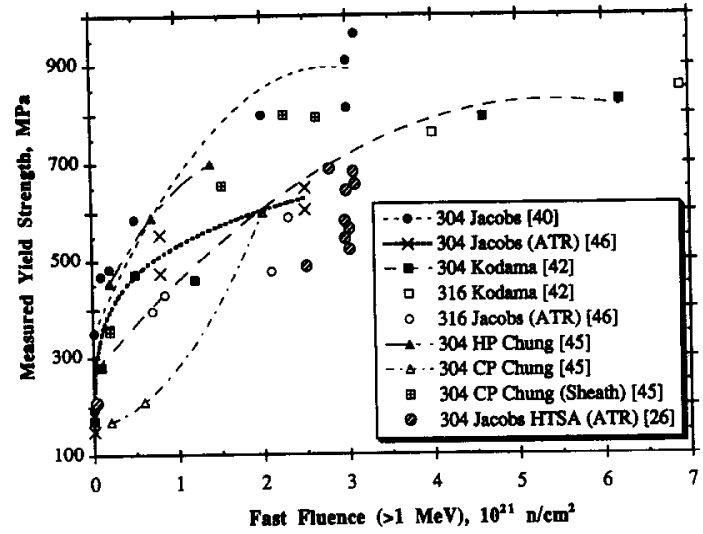

Fig. 19. Fast neutron fluence effects on the uniaxial yield strength for several 304 and 316 SS heats.

a function of irradiation dose are compared in Fig. 19. The 304 SS (BWR) data of Jacobs [40] are the most complete and are representative of the heats examined for IGSCC. A rapid rise in yield strength is observed with increasing fluence to about $900 \mathrm{MPa}$ at $3 \times 10^{21}$ $\mathrm{n} / \mathrm{cm}^{2}$ ( $\sim 4 \mathrm{dpa}$ ). ATR irradiations tend to show lower strengths that reach about $70 \%$ of the BWR data. Several differences among the data sets can be detected. Although strength increases with dose, the BWR-irradiated 304 SSs that cracked at lower fluences tend to have higher strengths. For example, the IGSCC-susceptible HP heat of Chung exhibits yield strengths more than double the more resistant $\mathrm{CP}$ absorber tube material.

Yield strength measurements are compared to IGSCC results in Fig. 20. Nearly all of the BWR-irradiated materials of Jacobs (304 SS) and Kodama (304 and 316 SS) fall very close to one another. Initial cracking in the SSR tests is seen only after the yield strength has increased to about $600 \mathrm{MPa}$ (more than 3 times the typical value for annealed stainless steel). In

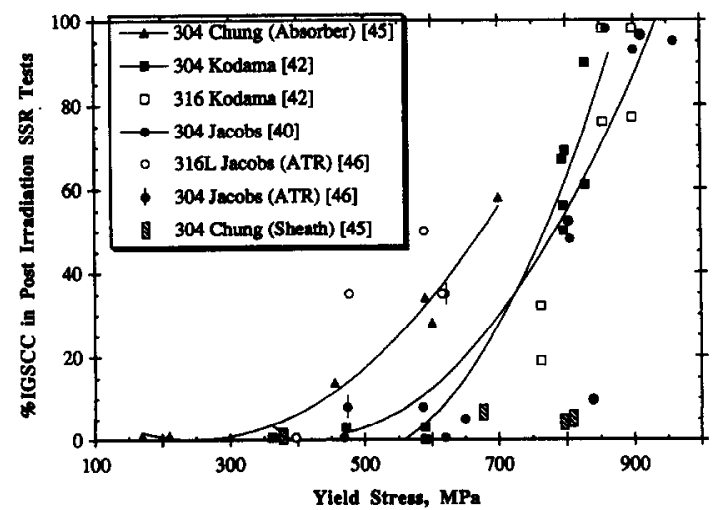

Fig. 20. Correlation between yield strength and IGSCC susceptibility for neutron-irradiated stainless steels. addition, the two absorber tube heats (HP and $\mathrm{CP}$ ) of Chung are now consistent with one another, reflecting the much higher strength and IG cracking measured for the HP material. However, the IGSCC vs. strength curve is shifted to lower strengths with initial cracking observed at $\sim 450 \mathrm{MPa}$ even though the SSR test environment is less aggressive. Interestingly, the ATRirradiated heats (304 and 316 SS) also show cracking at lower strengths. One heat having very high strength and very little IGSCC is the CP 304 SS sheath material of Chung. A large difference in the yield strengths required to promote IGSCC is evident between the sheath ( $800 \mathrm{MPa}$ ) and absorber (450 MPa) materials.

Many of the differences among data sets in Fig. 18 are accounted for by comparing to the material yield strength in Fig. 20. This indicates that the yield strength is a better measure of radiation damage than fluence. It also suggests that the radiation-induced hardening and microstructure may be playing a role in IASCC. Hardening alone does not appear to be sufficient to explain cracking susceptibility, but may act in combination with radiation-induced segregation. The hardened matrix will localize plastic deformation in grain boundary regions at loads below the macroscopic yield stress. At plastic strains, transgranular deformation characteristics will also be localized on specific planes after an initial dislocation has cleared a channel through the impeding loops. Phenomenologically, the change in yield strength is associated with hardening induced by dislocation loops and black dots, which are responsible for flow localization. If IG cracking can be associated with flow localization, then the change in yield strength may be expected to correlate better with \%IGSCC. However, such correlations produce fits no better than that shown in Fig. 20, partly because many experimenters did not report the unirradiated yield strength and this resulted in a sparser data set.

Radiation hardening in austenitic SSs results from the formation of small interstitial loops which effectively impede dislocation source operation and dislocation motion through the matrix. Bulk plasticity is limited to localized deformation within bands as illustrated by the charged-particle irradiations. [49] The low stacking fault energy in 304 SS makes the process of dislocation channeling difficult and promotes extensive twinning at low temperatures. A primary question is how this inhomogeneous deformation may influence IG failure. Manahan et al. [50] has shown that IG cracking can be induced in highly irradiated SSs without an environmental component if the strain rate is slow enough. However, it is well established that oxidizing, high-temperature water environments are required for IG cracking at low-to-moderate fluences $\left(<3 \times 10^{21} \mathrm{n} / \mathrm{cm}^{2}\right)$. Therefore, IASCC susceptibility may be a precursor to a more general IG embrittlement susceptibility in irradiated SSs. 
Slip planarity has long been identified as detrimental to SCC and hydrogen embrittlement resistance by promoting dislocation pileups and high local stresses. Since grain boundary ledges are an excellent stress concentration site and a primary dislocation source, these interfacial regions can achieve very high stresses. Under tensile loading, several options are available at the boundary to accomodate these high stresses including emission of dislocations which must eliminate, bypass or cut through matrix defects to form slip bands, creation of deformation twins, or boundary cracking. Deformation studies on irradiated copper indicated that dislocation channels form during plastic deformation, but reach a saturation width and density at relatively small strains [31]. In other words, dislocation channels may have a finite operation life before pile-ups are created to shut down the source and there exists a minimum spacing between these sources. This behavior is similar to that observed in the irradiated 304 SSs [51,52]. As available channels for plasticity are eliminated, local stresses may exceed the grain boundary cohesive energy and promote IG crack advance. The environmental effect on cracking could result from sharpening the IG crack tip by dissolution (increases local stress) and by supplying corrosion-induced hydrogen to the boundary region (decreases interfacial cohesive energy). Both of these processes will be sensitive to the radiation-induced grain boundary composition.

Intergranular cracking may also be promoted by localized plasticity within or near the boundary plane. Since the grain boundary is a sink for radiation-induced defects, a narrow region (on the order of nanometers) surrounding the interface may form which is free of dislocation loops. Grain boundary sliding and active slip on $\langle 111\rangle$ planes within this narrow zone may occur and could be enhanced by the presence of hydrogen. This process is more likely to occur in-core where continuous migration of vacancies and interstitials to grain boundaries will increase local diffusivities and dislocation mobilities. Localized plasticity of this type may act in concert with a decohesion mechanism to prompt IASCC. In both cases, hydrogen may play an important role. A more detailed interfacial characterization is necessary to determine how grain boundaries deform in irradiated SSs and to elucidate dynamic irradiation and deformation effects on dislocation activity.

\subsection{Radiation-induced chromium depletion and effects on IGSCC}

In stainless steels, major alloying elements such as iron, nickel and chromium, are directly influenced by the flow of radiation-induced vacancies to grain boundaries. The slowest diffusing element (nickel) becomes enriched at sinks, while faster diffusers (chromium and

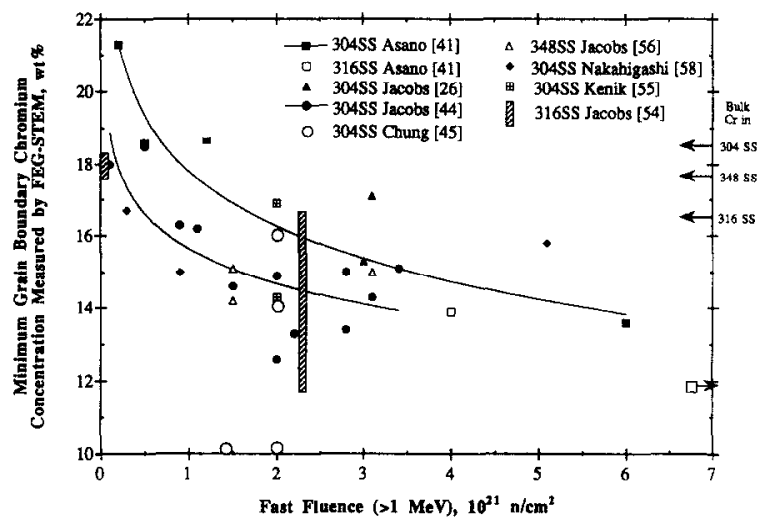

Fig. 21. Summary of reported measurements of the minimum grain boundary chromium concentration as a function of fast neutron fluence.

iron) are depleted. Undersized minor elements and impurities such as silicon and phosphorus bind with interstitials and migrate preferentially to sinks. Grain boundary composition has been reported in a number of neutron-irradiated SSs [23,25,41,44-46,53-58]. At present, the most complete data has been generated using FEG-STEM with an incident electron probe diameter from 2 to $3 \mathrm{~nm}$ and through-foil thicknesses less than $75 \mathrm{~nm}$. This results in an analysis resolution of about 3 to $5 \mathrm{~nm}$ that enables measurement of narrow, radiation-induced enrichment and depletion profiles.

Radiation-induced chromium depletion has been the focus of many IASCC studies because of its well documented effects in promoting IGSCC in sensitized stainless steels. Grain boundary chromium concentrations measured in neutron-irradiated 304, 316 and 348 SSs have been compiled and analyzed. Minimum chromium concentrations are plotted as a function of fluence in Fig. 21. The plotted data has been adjusted to account for the effect of chromium-rich surface films on the measured concentrations. Grain boundary concentrations have been reduced by the difference (typically $\sim 1 \%$ ) between the measured matrix chromium and the bulk content. No attempt has been made to deconvolute the measured profiles to more accurately determine the true interfacial concentration for these narrow profiles. However, as noted above, the minimum chromium level measured has been used. Numerous reasons exist why FEG-STEM may underestimate RIS in neutron-irradiated stainless steels (particularly at low fluences), but there are few reasons for the opposite to be true. Therefore, the values plotted in Fig. 21 are believed to better represent an upper bound on the grain boundary composition that controls SCC. It is likely that the actual minimum concentrations are below those reported due to beam dilution 


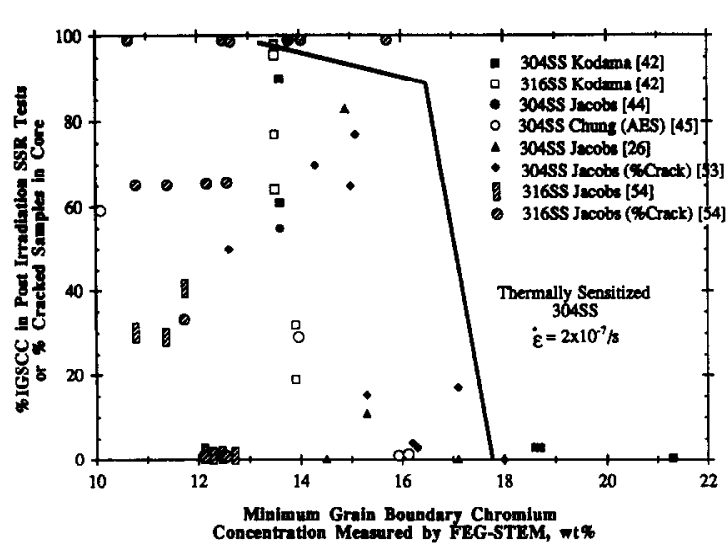

Fig. 22. Comparison between grain boundary chromium concentration and IGSCC susceptibility for neutron-irradiated stainless steels.

effects and the limited number (two per sample) of boundaries analyzed.

The most detailed characterization of neutron fluence effects on grain boundary RIS has been reported by Jacobs [25] on 304 SSs. A consistent decrease in interfacial chromium was detected with increasing fluence up to $\sim 2 \times 10^{21} \mathrm{n} / \mathrm{cm}^{2}$, i.e. about $3 \mathrm{dpa}$. Samples irradiated to slightly higher fluences did not show a continued decrease in the grain boundary chromium level. This change in the rate of depletion is in agreement with the few high-fluence data points in Fig. 21. The heat-to-heat variability is indicated by the more recent data of Jacobs et al. [54] on thirteen different heats of $316 \mathrm{SS}$ irradiated to a fast neutron fluence of $2.3 \times 10^{21} \mathrm{n} / \mathrm{cm}^{2}$. Grain boundary chromium depletion is observed in all heats, but the amount of measured depletion ranged from 2 to $9 \%$. Again only two boundaries were analyzed per material with considerable variability between the two reported measurements. Considering the wide range of materials and starting conditions, most data shows a consistent exponential decrease in chromium content with increasing fluence.

Data $[25,41,42,45,53-56]$ where radiation-induced chromium depletion and IGSCC have been measured are summarized in Fig. 22. The SSR tests are limited, but indicate that some level of depletion exists in all stainless steels which fail by IGSCC. As the grain boundary chromium concentration drops below $\sim 16$ wt\%, 304 SS becomes susceptible to cracking under the specific conditions of the test. The data points for 316 SS suggest a lower minimum, corresponding to an interfacial chromium depletion of $\sim 2 \mathrm{wt} \%$ below the matrix, consistent with the 304 SS results. Included in Fig. 22 are in-core eddy current measurements [25] and swelling mandrell test results [54] which indicate the extent of IGSCC based on the percentage of cracked components. Many differences exist between the in-situ straining tests and post-irradiation SSR tests, but data from each source only show cracking in samples with some degree of chromium depletion. Significant cracking is identified when chromium levels drop below 16 wt \%.

The relationship between thermally induced chromium depletion and IGSCC established by Bruemmer et al. $[29,59]$ has been plotted with the irradiated materials data in Fig. 22. All irradiated specimens that show IG cracking have sufficient grain boundary chromium depletion for IGSCC susceptibility in the SSR tests. Thus, chromium depletion can explain the observations of IGSCC without considering other radiation effects on microstructure and microchemistry. However, questions still remain as to why a few chromium-depleted SSs show more resistance to IGSCC. In particular, Jacobs et al. [54] identified very significant radiation-induced chromium depletion (down to $\sim 13.5 \mathrm{wt} \%$ ) in several $316 \mathrm{SS}$ heats which were resistant to IGSCC. Proton-irradiated high-purity 304-type SSs have also shown an improved cracking resistance in SSR tests for certain alloys exhibiting severe chromium depletion [60]. No correlation has been found between chromium content and IASCC. These results strongly suggest that other microstructural (e.g., radiation hardening) and/or microchemical (grain boundary or adjacent matrix) aspects influence cracking susceptibility. Since radiation-induced chromium depletion widths are very narrow, differences in deformation or passivation characteristics among SS heats may strongly impact crack initiation and growth processes.

Although this discussion has only considered radiation-induced chromium depletion, comparisons between grain boundary compositions and IASCC susceptibility can also be made for other segregants such as nickel, silicon and phosphorus. Since the measured enrichment of nickel is nearly always consistent with the depletion of chromium, similar relationships to IGSCC result. This is not the case for silicon and phosphorus since high-purity SSs (where neither segregates) show cracking, as do commercial alloys with significant impurity levels at the grain boundary. There is no clear evidence that other impurity elements (e.g., sulfur, boron or nitrogen) segregate during irradiation and impact IASCC susceptibility. As a result, if radiation-induced grain boundary segregation promotes IGSCC, chromium depletion appears to be responsible.

\section{Conclusions}

The fundamental understanding of the radiation-induced processes controlling IGSCC resistance of 
austenitic stainless steels has improved dramatically over the last ten years. Many aspects of the phenomena can be well explained (and predicted) based on the extensive experience with cracking of stainless steel piping in reactor water environments. This is particularly true for irradiation effects on water chemistry and its influence on electrochemical corrosion potential. In addition, a qualitative understanding of radiation-induced segregation processes has been developed, as well as high-resolution techniques to measure grain boundary compositions. However, the specific microstructural and micro-chemical components which promote IASCC remain a mystery. Well-controlled data from properly irradiated and properly characterized materials is sorely lacking due to the inherent experimental and financial difficulties. Recent research has eliminated many of the early theories of IASCC, but is far from establishing the mechanisms of cracking. Current work is moving from a focus on radiation microchemistries to radiation microstructures. Perhaps the most pressing need at present is an improved understanding of deformation in irradiated microstructures and its influence on IG cracking.

\section{Acknowledgements}

The authors wish to acknowledge various colaborators who had contributed directly to this research including M. Atzmon, J. Cookson, D. Damcott, R. Carter and T. Allen at the University of Michigan, E. Simonen, J. Brimhall, J. Vetrano and J. Cole at PNL and P. Andresen of the General Electric Company. Support for this research has been provided by the U.S. Department of Energy through Grants DE-FG0788ER12825 and DE-FG02-93ER12130, through the Materials Sciences Branch, Office of Basic Energy Sciences under Contract DE-AC06-76RLO 1830 and Grant DE-FG02-93ER-12130, and the General Electric Company.

\section{References}

[1] G.S. Was and P.L. Andresen, J. Metals 44 (1992) 8.

[2] M.J. Norgett, M.T. Robinson and I.M. Torrens, Nucl. Eng. Des. 33 (1975) 50.

[3] A.J. Jacobs and G.P. Wozadlo, Corrosion 91, National Association of Corrosion Engineers, Houston, TX, paper No. 41.

[4] P.L. Andresen, F.P. Ford, S.M. Murphy, J.M. Perks, Proc. 4th Int. Symp. on Environmental Degradation of Materials in Nuclear Power Systems - Water Reactors. (NACE, 1990) pp. 1-83 to 1-121.

[5] F.P. Ford and P.L. Andresen, Proc. Environmental
Degradation of Materials in Nuclear Power Systems Water Reactors, eds. G.J. Theus, J.R. Weeks (The Metallurgical Society of AIME, Warrendale, 1988) p. 789.

[6] P.L. Andresen and F.P. Ford, Mater. Sci. Eng. A103 (1988) 167.

[7] P.R. Okamoto and L.E. Rehn, J. Nucl. Mater. 83 (1979) 2.

[8] N.Q. Lam, A. Kumar and H. Wiedersich, Effects of Radiation on Materials, 11th Conf., ASTM-STP782, H.R. Brager and J.S. Perrin, (American Society for Testing and Materials, 1982) p. 985.

[9] A.C. Hindmarsh, Lawrence Livermore Laboratory Report UCID-30002, (1974).

[10] J.M. Perks, A.D. Marwick and C.A. English, Proc. Conf. on Radiation-Induced Sensitisation of Stainless Steels, ed., D.I. Norris (Central Electricity Generating Board, Berkeley Nuclear Labs, Berkeley, Gloucestershire, 1987) p. 15.

[11] E. Simonen, private communication.

[12] G.H. Kinchen and R.S. Pease, Rep. Prog. Phys. 18 (1955) 1.

[13] L.E. Rehn, J. Nucl. Mater. 174 (1990) 144.

[14] L.K. Mansur and K. Farrell, J. Nucl. Mater. 170 (1990) 236.

[15] T. Kato, H. Takahashi, S. Ohnuki, K. Nakata and J. Kuniya, J. Nucl. Mater. 179-181 (1991) 623.

[16] D. Damcott, D. Carter, J. Cookson, J. Martin, M. Atzmon and G.S. Was, Radiot. Eff. Def. Solids 118 (1991) 383.

[17] S. Bruemmer, J. Nucl. Mater. 186 (1991) 13.

[18] A.J. Jacobs and G.P. Wozadlo, Corrosion 91, National Association of Corrosion Engineers, Houston, TX, 1991, paper No. 41.

[19] V. Naundorf, J. Nucl. Mater. 182 (1991) 254.

[20] L.E. Rehn and H. Wiedersich, in Surface Alloying by Ion, Electron and Laser Beams, eds. L.E. Rehn, St. T. Picraux and $\mathrm{H}$. Wiedersich (American Society for Metals, Metals Park, $\mathrm{OH}, 1986)$ p. 137.

[21] V.K. Sethi and P.R. Okamoto, in Phase Stability During Irradiation, eds. J.R. Holland, L.K. Mansur and D.I. Potter (The Metallurgical Society of AIME, Warrendale, 1981) p. 109.

[22] R.D. Carter, D.L. Damcott, M. Atzmon, G.S. Was and E.A. Kenik, J. Nucl. Mater. 205 (1993) 361.

[23] F.A. Garner and H.R. Brager, J. Nucl. Mater. 133 \& 134 (1985) 511.

[24] A. Azarian and K. Kheloufi, J. Nucl. Mater. 97 (1981) 25.

[25] A.J. Jacobs, Relationship of grain boundary composition in irradiated type 304SS to neutron fluence and IASCC, 16th ASTM Symp. on Radiation Effects on Materials, Denver, 1992.

[26] A.J. Jacobs, G.E.C. Bell, C.M. Shepherd and G.P. Wozadlo, Proc. 5th Int. Symp. on Environmental Degradation of Materials in Nuclear Power Systems - Water Reactors, ed. D. Cubicciotti (American Nuclear Society, La Grange Park, IL, 1992) p. 917.

[27] D.I.R. Norris, C. Baker and J.M. Titchmarsh, Proc. Conf. on Radiation-Induced Sensitisation of Stainless Steels, ed. D.I. Norris (Central Electricity Generating Board, Berkeley Nuclear Laboratories, Berkeley, Gloucestershire, 1987) p. 86. 
[28] S.M. Bruemmer and G.S. Was, in these Proceedings, J. Nucl. Mater. 216 (1994) 348.

[29] S.M. Bruemmer, B.W. Airey and L.A. Charlot, Corrosion 48 (1992) 42.

[30] S.J. Zinkle and B.N. Singh, J. Nucl. Mater. 199 (1993) 173.

[31] P.J. Maziasz and C.J. McHargue, Int. Mater. Rev. 32 (1987) 190.

[32] G.R. Odette and G.E. Lucas, J. Nucl. Mater. 179-181 (1991) 572.

[33] G. Odette, P. Maziasz and J. Spitznagel, J. Nucl. Mater., $85 \& 86$ (1979) 1289.

[34] P. Maziasz, Effects of Helium on Microstructural Development in Type 316 Stainless Steel Under Neutron Irradiation, ORNL-6121 (1985).

[35] E.E. Bloom, in Radiation Damage in Metals, eds. N.L. Peterson and S.D. Harkness, (American Society for Metals, Metals, Park, OH, 1976) p. 295.

[36] F.P. Ford, D.F. Taylor, Pl.L. Andresen and R.G. Ballinger, NP-5064M, Electric Power Research Institute, Palo Alto, CA (1987).

[37] P.L. Andresen and F.P. Ford, Modeling of irradiation effects on stress corrosion crack growth rates, paper No. 497, Corrosion/89 (NACE, Houston, 1989).

[38] P.L. Andresen, in Stress Corrosion Cracking, ed. R.H. Jones (American Society for Metals, Metals Park, $\mathrm{OH}$, 1992) p. 181

[39] V.Z. Jankus and R.W. Weeks, Nucl. Eng. Des. 18 (1972) 83.

[40] A.J. Jacobs, D.A. Hale and M. Siegler, unpublished data, GE Nuclear Energy, San Jose, CA, January 1986.

[41] K. Asano, K. Fukuya, K. Nakata and M. Kodama, Changes in grain boundary composition induced by neutron irradiation on austenitic stainless steels, Proc. 5th Int. Symp. on Environmental Degradation of Materials in Nuclear Power Systems - Water Reactors, ANS, Monterey, CA, (American Nuclear Society, La Grange Park, IL, 1992) p. 838.

[42] M. Kodama, S. Nishimura, J. Morisawa, S. Shima, S. Suzuki, and M. Yamamoto, Effect of fluence and dissolved oxygen on IASCC in austenitic stainless steel, Proc. 5th Int. Symp. on Environmental Degradation of Materials in Nuclear Power Systems - Water Reactors, ANS, Monterey, CA, (American Nuclear Society, La Grange Park, IL, 1992) p. 948.

[43] L.G. Ljungberg, unpublished Data, ABB Atom, Vasteras, Sweden, 1989. Data presented at the ICG-IASCC Meeting, Boston, MA, April 1989.

[44] S.M. Bruemmer and E.P. Simonen, Radiation hardening and radiation-induced chromium depletion effects on intergranular stress corrosion cracking of stainless steels, Corrosion 93 (National Association of Corrosion Engineers, Houston, 1993) paper 616.

[45] H.M. Chung, W.E. Ruther, J.E. Sanecki and T.F. Kassner, Irradiation-induced sensitization and stress corrosion cracking of type 304 stainless steel core-internal components, ibid. Ref. [6] p. 511. Also Semi-Annual
Reports, Environmentally Assisted Cracking in Light Water Reactors, NUREG/CR-4667, vols. 13 and 14 (Nuclear Regulatory Commission, 1992).

[46] A.J. Jacobs, G.P. Wazadlo, K. Nakata, T. Yoshida and I. Masaoka, Proc. 3rd Int. Symp. on Environmental Degradation of Materials in Nuclear Power Systems - Water Reactors, eds. G.J. Theus and J.R. Weeks (AIME, 1987) p. 243.

[47] W.L. Clarke and A.J. Jacobs, eds. Effects of radiation environment on SCC of austenitic materials, Corrosion 1983 (NACE, 1983) p. 451.

[48] K. Nakata, J. Int. Metals Japan, 52, (1988) 1023, 1167.

[49] S.M. Bruemmer, J.I. Cole, J.L. Brimhall, R.D. Carter and G.S. Was, Proc. 6th Int. Symp. on Environmental Degradation of Materials in Nuclear Power Systems Water Reactors, eds. R.E. Gold and E.P. Simonen (TMS, 1993) p. 537.

[50] M.P. Manahan, R. Kohli, J. Santucci and P. Sipush, Nucl. Eng. Des. 113 (1989) 297.

[51] M.S. Wechsler, in The Inhomogeneity of Plastic Deformation, ed. R.E. Reed-Hill, (American Society for Metals, 1973) chap. 2, p. 19.

[52] I.V. Gorynin, O.A. Kozhevnikov, K.A. Nikishina, A.M. Parshin and V.M. Sedov, Fiizika Radiatsionnykh i Povrezhdenii Radiatsionnoe Materialovedenie, 3(26) (1983) 45.

[53] A.J. Jacobs, R.E. Clausing, L. Heatherly and R.M. Kruger, Irradiation-assisted stress corrosion cracking and grain boundary segregation in heat treated type 304 SS, 14th Int. Symp. on Radiation Effects on Materials, Andover, MA, 1988.

[54] A.J. Jacobs, G.P. Wazadlo, K. Nakata, S. Kasahara, T. Okada, S. Kawano and S. Suzuki, The correlation of grain boundary composition in irradiated stainless steel with IASCC resistance, Proc. 6th Int. Symp. on Environmental Degradation of Materials in Nuclear Power Systems - Water Reactors, eds. R.E. Gold and E.P. Simonen (TMS, 1993) p. 597.

[55] E.A. Kenik, J. Nucl. Mater. 187 (1992) 239.

[56] A.J. Jacobs, R.E. Clausing, M.K. Miller and C.M. Shepherd, Influence of grain boundary composition on the IASCC susceptibility of Type 348-stainless steel, ibid. Ref. [4] p. 14-21.

[57] C.M. Shepherd and T.M. Williams, Simulation of microstructural aspects of IASCC in water reactor core components, ibid. Ref. [4], p. 14-11.

[58] S. Nakahigashi, M. Kodama, K. Fukuya, S. Nishimura, S. Yamamoto, K. Saito and T. Saito, J. Nucl. Mater. 179-181 (1991) 1061.

[59] S.M. Bruemmer, B.W. Arey and L.A. Charlot, Grain Boundary Chromium Concentration Effects on the IGSCC and IASCC of Austenitic Stainless Steels, ibid. Ref. [54] in press.

[60] J. Cookson, R.D. Carter, D.L. Damcott, G.S. Was and P.L. Andresen, The role of microchemical and microstructural effects in the IASCC of high-purity austenitic stainless steels, ibid. Ref. [54], p. 573. 